\title{
Neural Correlates of Direct and Reflected Self-Appraisals in Adolescents and Adults: When Social Perspective-Taking Informs Self-Perception
}

\author{
Jennifer H. Pfeifer \\ University of Oregon
}

\author{
Carrie L. Masten, Larissa A. Borofsky, \\ Mirella Dapretto, Andrew J. Fuligni, \\ and Matthew D. Lieberman \\ University of California, Los Angeles
}

\begin{abstract}
Classic theories of self-development suggest people define themselves in part through internalized perceptions of other people's beliefs about them, known as reflected self-appraisals. This study uses functional magnetic resonance imaging to compare the neural correlates of direct and reflected self-appraisals in adolescence ( $N=12$, ages 11-14 years) and adulthood ( $N=12$, ages 23-30 years). During direct self-reflection, adolescents demonstrated greater activity than adults in networks relevant to self-perception (medial prefrontal and parietal cortices) and social-cognition (dorsomedial prefrontal cortex, temporal-parietal junction, and posterior superior temporal sulcus), suggesting adolescent self-construals may rely more heavily on others' perspectives about the self. Activity in the medial fronto-parietal network was also enhanced when adolescents took the perspective of someone more relevant to a given domain.
\end{abstract}

Three highly active areas of current research in adolescent social development include family relations, peer relations, and self-development (Steinberg \& Morris, 2001). At the intersection of these fields lies a question that has been debated for decades: To what extent is our self-image relatively independent versus being reliant on our perceptions of how others (particularly peers and family members) view us (Baldwin, 1895; Cooley, 1902; Mead, 1934)? On the one hand, adolescence is a time during which autonomy increases, particularly in the form of independence from parents

This research was supported by a National Research Service Award from the National Institute of Mental Health (MH075299) to J. H. Pfeifer and a UCLA Academic Senate Grant to M. Lieberman. It was also funded in part by the Foundation for Psychocultural Research through grants to the FPR-UCLA Center for Culture, Brain, and Development and to A. J. Fuligni. For generous support, the authors also wish to thank the Brain Mapping Medical Research Organization, Brain Mapping Support Foundation, Pierson-Lovelace Foundation, the Ahmanson Foundation, William M. and Linda R. Dietel Philanthropic Fund at the Northern Piedmont Community Foundation, Tamkin Foundation, Jennifer Jones-Simon Foundation, Capital Group Companies Charitable Foundation, Robson Family, and Northstar Fund. The project described was supported by Grants RR12169, RR13642, and RR00865 from the National Center for Research Resources (NCRR), a component of the National Institutes of Health (NIH); its contents are solely the responsibility of the authors and do not necessarily represent the official views of NCR or NIH.

Correspondence concerning this article should be addressed to Jennifer H. Pfeifer, Department of Psychology, 1227 University of Oregon, Eugene, OR 97403-1227. Electronic mail may be sent to jpfeifer@uoregon.edu.
(Steinberg \& Silverberg, 1986). Yet on the other hand, self-perceptions and associated behaviors are clearly dependent on social contexts-teenagers view themselves and behave differently with friends than with family members, and so on (Harter, Bresnick, Bouchey, \& Whitesell, 1997; Harter, Waters, \& Whitesell, 1998). In this study, we investigate how adolescent self-perceptions are related to viewing oneself through the eyes of these important others, a valuable but frequently overlooked way to examine the relation between social context and self-development. Furthermore, we do so using neuroimaging techniques, for a novel "developmental social cognitive neuroscience" perspective on the connection between family relations, peer relations, and selfdevelopment during adolescence.

\section{Background}

Symbolic interactionism, one of the oldest and most influential psychological theories of selfdevelopment, focuses on others' contributions to the self-concept by proposing that in various ways, we internalize others' beliefs about ourselves (Baldwin, 1895; Cooley, 1902; Mead, 1934). This approach emphasizes one internal process in

(C) 2009, Copyright the Author(s)

Journal Compilation (c) 2009, Society for Research in Child Development, Inc. All rights reserved. 0009-3920/2009/8004-0007 
particular that shapes self-knowledge: taking someone else's perspective of the self, which produces reflected self-appraisals. Across development, reflected self-appraisals (what I think you think of me) were hypothesized to evolve into direct self-appraisals (what I think of myself), as the perspective-taking component was routinized, internalized, and then rendered unnecessary.

Comparing direct and reflected self-appraisals, particularly in children and adolescents, thus represents one straightforward way through which to examine how other individuals may impact selfdevelopment. Influential studies and reviews of self-appraisal processes tend to suggest the effect of others on self-development is relatively minor in practice-while direct self-appraisals may shape reflected self-appraisals and to a lesser extent vice versa, the actual appraisals of others have a limited influence on direct and reflected self-appraisals (Felson, 1993; Ichiyama, 1993; Kenny \& DePaulo, 1993; Shrauger \& Schoeneman, 1979; Tice \& Wallace, 2005). However, the samples relied on to derive these conclusions were weighted heavily toward adults of college age or older. One exception is the programmatic work conducted on adolescents by Felson and his colleagues (Felson, 1980, 1981, 1985, 1993; Felson \& Reed, 1986a, 1986b), which demonstrated that there was a high degree of shared variance between direct self-perceptions, objective indicators of self-relevant evaluative information, and others' perceptions of the self. Nevertheless, having relatively few studies with child or adolescent samples may affect our interpretations of previous work because theoretically, reflected self-appraisals in basic domains should already be incorporated into an individual's self-concept by adulthood. Therefore, it is not surprising that the importance of reflected self-appraisals has not been fully evident in existing research. Some of the most recent work in younger samples continues to support the proposition that actual appraisals made by peers, parents, and teachers are associated with reflected and direct self-appraisals in primary domains such as academics, athletics, social competence, and behavioral conduct (Harter, 1999) —and in turn, these associations impact real developmental outcomes (Cole, 1991; Cole, Maxwell, \& Martin, 1997; Harter et al., 1998). For example, adolescents who reported believing that others saw them as rule violators were more likely to actually engage in delinquent behavior (Bartusch \& Matsueda, 1996), and adolescents who made positive reflected self-appraisals from their parents' perspectives about their academic competence demonstrated better performance in math and science (Bouchey \& Harter, 2005).

The potential consequences of reflected selfappraisals for adolescent development have nevertheless resulted in only a fraction of research when compared with that conducted on direct selfappraisals (including self-concepts and self-esteem). Such a limited number of developmental studies examining reflected self-appraisal processes may have resulted in part from a relatively intractable methodological problem: Direct self-appraisals and reflected self-appraisals are reported by the same individual, making it difficult to determine how each colors the other at any given point in time. In light of this concern, we propose taking a developmental social cognitive neuroscience approach to reinvigorate this line of research.

Via neuroimaging techniques, we can examine how reflected appraisals are similar to or different from direct appraisals at the neural level; in other words, we can potentially ameliorate the issues associated with self-report biases by transitioning from analyzing the content of self-appraisals to focusing on the neurocognitive systems that support the processes of making direct and reflected self-appraisals. Here, we utilize functional magnetic resonance imaging (fMRI) during reflected and direct self-appraisal task conditions to quantify relative differences in the blood oxygenation leveldependent (BOLD) signal, an indirect measure of task-driven neuronal activity influenced by changes in cerebral blood volume, cerebral blood flow, and oxygen consumption (Logothetis \& Wandell, 2004). Once the neural systems contributing to direct and reflected self-appraisals are identified by this mechanism, we can borrow from cognitive neuroscience research to make inferences about the common and unique processes involved (Lieberman \& Pfeifer, 2005; Ochsner \& Lieberman, 2001). This may help us generate new hypotheses about the role of reflected self-appraisals during adolescence, including their association with family and peer relations as well as their impact on self-views.

\section{Relevant Neuroimaging Research}

Self-perception. The neural systems supporting direct self-appraisal processes, also referred to as self-reflection or self-knowledge retrieval, have been studied for over a decade. Neuroimaging studies of general self-knowledge retrieval typically ask adults to respond whether trait words or phrases describe themselves, recall autobiographical memories, or reflect on one's preferences (for a 
review, see Lieberman, 2007). Retrieving this kind of self-knowledge, in contrast to other tasks (e.g., semantic knowledge retrieval), is frequently associated with relatively greater activity in medial prefrontal cortex (MPFC; putative Brodmann's area [BA] 10 and 32) as well as precuneus and posterior cingulate in medial posterior parietal cortex (MPPC; BA 7 and 31; D'Argembeau et al., 2005, 2007; Fink et al., 1996; Heatherton et al., 2006; Johnson et al., 2002; Kelley et al., 2002; Lieberman, Jarcho, \& Satpute, 2004). In addition, the first inquiry into the neural correlates of general selfknowledge retrieval processes in a developmental sample suggests that 9- to 10-year-old children have demonstrated both similarities and differences in comparison to adults during direct self-appraisals: the regions implicated (MPFC and MPPC) are the same, but children show significantly enhanced activity in MPFC compared to adults (Pfeifer, Lieberman, \& Dapretto, 2007).

The functions of this medial fronto-parietal network in MPFC and MPPC are probably not unique to direct self-appraisals (Gillihan \& Farah, 2005). For example, in one study direct appraisals about the self, appraisals of a close other, and reflected appraisals from the perspective of that close other about oneself all engaged MPFC and MPPC to a similar extent (Ochsner et al., 2005), although another study found enhanced activity in MPFC during direct self-appraisal compared to thinking about the traits possessed by one's best friend (Heatherton et al., 2006). In addition, MPPC has been implicated in other common social cognitive functions that are not exclusively relevant to the self, including episodic memory, mental imagery, perspective-taking, and a sense of agency (Cabeza \& Nyberg, 2000; Cavanna \& Trimble, 2006; Maguire, Frith, \& Morris, 1999; Ruby \& Decety, 2004; Vogeley et al., 2001). A working consensus of the research may be that MPFC is indeed a region essential to self-knowledge processes, although it may also support our understanding of other individuals under certain conditions (Mitchell, Banaji, \& Macrae, 2005; Mitchell, Macrae, \& Banaji, 2006), and MPPC is likewise implicated in both self and interpersonal understanding.

Social perception. In theory, reflected self-appraisals should involve both self-focus and social perception, as they require considering the beliefs of another individual about the self. If this is indeed the case, what neural systems might be involved in reflected self-appraisals in addition to MPFC and MPPC? Thus far, only two studies have examined the neural correlates of reflected self-appraisals.
There is some degree of overlap in the findings across the two studies: Both reported a high degree of similarity overall between direct and reflected self-appraisals and both found that reflected selfappraisals may be associated with more activity in orbitofrontal and insular cortex, as well as the lingual gyrus (D'Argembeau et al., 2007; Ochsner et al., 2005). However, we can also gather clues about candidate regions that may be involved in the reflected appraisal process from other lines of research.

Reviews of social cognitive neuroscience studies have consistently highlighted four key regions involved in mentalizing and other unique aspects of human social-cognition: temporal-parietal junction (TPJ), dorsal MPFC (DMPFC), posterior superior temporal sulcus (pSTS), and the temporal poles (Frith \& Frith, 2003, 2006; Saxe, 2006). Third-person perspective-taking processes, including reasoning about another individual's beliefs or mental states, seem to engage a region at the intersection of inferior parietal lobule and posterior superior temporal gyrus, also known as the TPJ (BA 22/39/40; Aichhorn, Perner, Kronbichler, Staffen, \& Ladurner, 2006; Apperly, Samson, Chiavarino, \& Humphreys, 2004; D'Argembeau et al., 2007; Ruby \& Decety, 2003; Samson, Apperly, Chiavarino, \& Humphreys, 2004; Saxe \& Kanwisher, 2003; Saxe \& Wexler, 2005). Similarly, DMPFC is often engaged in tasks of mental state attribution and impression formation (Mitchell, Macrae, \& Banaji, 2005; Mitchell et al., 2005, 2006). The pSTS is most likely responsible for extracting information about goals and intentions from biological motion within a social context (Pelphrey, Morris, \& McCarthy, 2004; Pelphrey, Viola, \& McCarthy, 2004). Finally, the temporal poles may be a storehouse of social and personal semantic knowledge, providing linkages between perceptions and emotions (Olson, Plotzker, \& Ezzyat, 2007). Making a reflected selfappraisal by definition involves representing someone else's beliefs-in particular, the perception of another's belief about oneself-and thus these triadic processes revolving around mental states (what do I think you think of me?) may be particularly likely to engage TPJ and/or DMPFC.

Developmental trajectories. Relatively little research has explored changes in the functionality of the brain regions highlighted above (MPFC, MPPC, DMPFC, TPJ, pSTS, temporal poles, orbitofrontal cortex, and insula). One study examining the neural bases of communicative intent found that taskrelated activity in DMPFC associated with irony comprehension was negatively correlated with age, 
while task-related activity in the fusiform gyrus was positively correlated with age, suggesting there may be some automatization of basic mentalizing processes with development (Wang, Lee, Sigman, \& Dapretto, 2006). Another review focusing on rostral prefrontal cortex (both lateral and medial aspects of BA 10) reported a similar pattern wherein adults engaged this region less than children or adolescents, although this evidence was drawn primarily from tasks assessing response inhibition and response competition (Dumontheil, Burgess, \& Blakemore, 2008). Finally, a recent longitudinal study of brain structure in 375 typically developing individuals found that MPFC, DMPFC, MPPC, TPJ, temporal poles, orbitofrontal cortex, and anterior insula all follow cubic developmental trajectories of cortical thickness: increases in childhood followed by decreases in adolescence and eventual stability in young adulthood (Shaw et al., 2008). In summary, all of the regions identified by previous neuroimaging research as candidates likely to support reflected and direct self-appraisal processes may undergo structural and/or functional development throughout childhood and adolescence.

\section{Rationale for the Present Study}

The above review demonstrates that conducting neuroimaging studies comparing reflected and direct self-appraisals is clearly warranted to inform current research on self-development in adolescence, as well as to better understand the neural systems supporting each process. We can think of at least three reasons for developmental research to take a social neuroscience perspective and social neuroscience research to take a developmental perspective, as well as specifically for this line of work to include adolescent participants. The first is that during adolescence, the brain regions involved in self- and social perception are undergoing important changes. Structurally, gray matter is stabilizing after a decrease in the maximal cortical thickness characteristic of childhood. Functionally, the cognitive processes carried out by these neural systems may display increasing levels of efficiency, as abilities that first emerge in childhood (such as mentalizing or social and temporal comparisons of the self with others) become more routine.

Second, it is possible that asking a 26-year old to make a self-appraisal may capture merely vestigial remnants of processes that 13-year olds engage in quite frequently. After all, the attributes tapped in previous studies were common personality traits, like sociable or daring. For nearly all of these qualities, it can be argued, adult participants likely had a strong sense of the degree to which each trait was self-descriptive (while adolescents may still be in the process of determining whether such a trait describes them or not). Therefore, examining the neural processes supporting reflected and direct self-appraisals in adolescents may enhance the psychological relevance of the task demands and better demonstrate how reflected appraisals contribute to self-development. If indeed reflected appraisals play a role in self-definition during this period, one might speculate that direct self-appraisals will engage the additional neural systems that reflected appraisals do, because of a propensity to continue to employ the reflected appraisal process even when not explicitly instructed to do so. In other words, reflected self-appraisals may in fact represent how teenagers answer direct self-appraisal questions, whereas adults may no longer make this processing substitution (Kahneman, 2003). Perhaps adolescence could even be viewed as the apex of reflected appraisals' influence due to social transitions, such as a growing reliance on peers and an increased sensitivity to peer evaluations, as well as the development of advanced perspective-taking skills that facilitate at least the ability to reason about others' viewpoints, if not accurately discern them (Lapsley, 1993; Vartanian, 1997, 2000; Vartanian \& Powlishta, 1996).

Third, adolescents must negotiate an escalating number of social contexts, and to do so may emphasize feedback from the source(s) most relevant to each domain (Harter, 1999). It is well established that the self-concept is hierarchically organized by domains, within which perceptions of the self's attributes and abilities contribute to domain-relevant behaviors and outcomes, and across which give rise to one's global self-image (Bracken, 1996; Damon \& Hart, 1988; Harter, 1999; Marsh, 1990a, 1990b; Rosenberg, 1979; Wigfield et al., 1997). Most pertinent to this investigation is the likelihood that on the one hand, reflected selfappraisals from parental perspectives may be more important in academic domains that adolescents view as both more important to parents, and more closely monitored by them; on the other hand, reflected self-appraisals from peers' perspectives may be more salient in social domains, where opinions of peers are likely to be more relevant to adolescents. Studies have shown that parents play an important role in fostering academic achievement across childhood and adolescence and that one of the primary ways parents influence 
academic outcomes is through the perceptions that adolescents form about their parents' attitudes, expectations, and values related to school achievement, including their parents' beliefs regarding their school performance and ability (Bouchey \& Harter, 2005; Chen \& Lan, 1998; Shearin, 2002). For example, Bouchey and Harter (2005) found that reflected self-appraisals related to competence in math and science made by middle school students from their parents' perspectives predicted their own self-appraisals of competence, academic values, and actual performance in math and science. In contrast, extensive research has suggested that during adolescence, peers have a greater influence on social behaviors and self-views in social domains than do parents (Gardner \& Steinberg, 2005; Hyatt \& Collins, 2000; Marshal \& Chassin, 2000; Simons-Morton, Hartos, \& Haynie, 2004). Particularly during middle school, when peers take on increasing importance (Brown, 2004; Steinberg \& Silverberg, 1986), this heightened influence is likely related to a desire to "fit in" and attain high social status and popularity. For example, many of the antisocial and risky behaviors that increase during adolescence are associated with perceived popularity among peers (Eccles et al., 1993; Juvonen, Graham, \& Schuster, 2003), suggesting what teenagers perceive themselves to be and do may be adjusted according to beliefs about what peers value, even when it is maladaptive. If various evaluative sources of information about the self (e.g., peers or family members) are differentially relevant across domains, perhaps particular neural systems supporting self-reflection or other social cognitive processes including mentalizing and perspectivetaking may be more engaged when adolescents make reflected self-appraisals in a domain that "matches" the source's sphere of influence according to current behavioral research in developmental psychology (i.e., taking the perspective of a parent about one's academic abilities, and taking the perspective of a peer about one's social attributes).

\section{Summary and Hypotheses}

In summary, this study will provide the following significant advances to the body of research examining direct and reflected self-appraisal processes. First, this study represents a potential paradigm shift for developmental research, utilizing a new technique (fMRI) that shifts emphasis from the contents of direct and reflected self-appraisals to the processes involved in each. Second, we compare an adult sample with a younger sample: ado- lescents (11-14 years of age) attending middle school. Focusing on an age period when reflected self-appraisals may be relatively more frequently engaged in, as well as more relevant to one's selfimage, may be more likely to reveal significant neural contributions to these processes. Third, we use a task requiring direct and reflected self-appraisals in two basic domains (academic and social), across multiple perspectives (parents and peers), enabling us to focus on domains in which the perspectives of specific evaluative sources may be especially relevant for adolescents.

We hypothesize that:

1. Direct and reflected appraisals will be more similar in adolescents than in adults, in the sense that direct self-appraisals will exhibit more characteristics of reflected self-appraisals in adolescents than adults. Given that previous research suggests adolescent self-views are likely to be associated with the perceived opinions of others, adolescent (but not adult) direct self-appraisals may engage the neural systems associated with reflected self-appraisals and social-cognition more generally. Furthermore, direct self-appraisals made by adults in basic domains (i.e., those that have developed many years earlier) may be relatively routinized and thus involve the least amount of processing, compared with all other conditions. Therefore, we hypothesize that adult direct self-appraisals will elicit activity in areas known to be involved in selfreferential cognition (MPFC and MPPC), while adult reflected self-appraisals (and all self-appraisals made by adolescents) may also engage regions involved in social perception (TPJ, DMPFC, pSTS, and temporal poles) and those previously observed in studies of reflected self-appraisals in adults (orbitofrontal and insular cortex). These eight areas constitute our a priori regions of interest (ROIs) throughout the study.

2. Replicating our previous work, direct selfappraisals will engage MPFC more strongly in adolescents than in adults.

3. For our adolescent sample only, we made an additional prediction that the match identified in previous behavioral literature between the source of evaluation and the self-concept domain may influence reflected self-appraisal processes. That is, taking the perspective of a parent in the academic domain, and/or a peer in the social domain, may more strongly 
engage the neural systems in our a priori ROIs supporting self-reflection or other facets of social-cognition.

\section{Method}

\section{Participants}

Participants included 12 typically developing adolescents (5 males and 7 females), ranging in age from 11.3 to 13.7 years $(M=12.7, S D=0.8$ years $)$, and 12 normal adults (6 males and 6 females), ranging in age from 22.6 to 30.4 years $(M=25.7, S D=$ 2.1 years). Adolescents were recruited via flyers distributed at summer camps and posted in the community surrounding University of California, Los Angeles (UCLA), as well as from a pool of individuals who had participated in previous neuroimaging research and agreed to be contacted for future studies. All adolescents had begun middle school by the time they participated in the study. Adults were recruited from the UCLA graduate student population, and were all enrolled in school at the time of their participation. All participants were screened for significant psychiatric, medical, and neurological disorders using a medical questionnaire (completed by parents of adolescent participants) and a neurological exam performed by the researchers on the day of participation (Mutti, Sterling, Martin, \& Spalding, 1988). For a subset (8 of 12) of the participating adolescents, verbal IQ was assessed within 1-2 months of their scan via the Wechsler Abbreviated Scale of Intelligence (Wechsler, 1999). All adolescent and adult participants included were Caucasian, because ethnicity and cultural heritage may interact with perceptions of family members and peers. Written informed consent (ages 13 and up) or assent (ages 11-12) was obtained from every participant, and parents of adolescent participants provided written informed parental consent, according to guidelines outlined by the UCLA Institutional Review Board.

\section{Procedures}

Stimuli. The task used during the fMRI scan consisted of 40 unique, self-descriptive phrases adapted from stimuli used in Pfeifer et al. (2007). These stimuli included an equal number of positively and negatively valenced phrases, and represented two domains relevant to adolescents' school context-social competence and verbal academic ability. By crossing domain and valence, stimuli were designed to describe four stereotypical catego- ries of adolescents: individuals with high social competence, individuals with low social competence, individuals with high verbal academic ability, and individuals with low verbal academic ability. Additional pilot testing of the original stimuli resulted in slight modifications of some phrases to ensure their relevance to adolescent participants, and so as not to require the taking of more than one additional perspective (e.g., to report whether your mother thinks your teachers think you are a bad speller). Sample phrases for each category include: "I am popular," "I often get teased at school," "I read very quickly," and "I always spell things wrong." Valence was varied to prevent participants from developing a response strategy, thus positive and negative items for each domain were intermixed during stimulus presentation.

Direct and reflected self-appraisal task. While being scanned, participants heard verbal instructions directing them to make either direct self-appraisals or reflected self-appraisals from the perspectives of their mom, best friend, or classmates. Before each set of direct self-appraisals, participants heard the instructional cue: "What do $I$ think about myself? True or false, $I$ think..." followed by a series of 10 phrases (5 positive and 5 negative from a given domain). Before each set of reflected appraisals, participants heard a similar instructional cue indicating which perspective they should take, for example: "What does my mom think about me? True or false, my mom thinks..." followed by the same series of 10 phrases. Participants heard each series of 10 phrases four times in a row, each time preceded by an instructional cue directing them to take a different perspective. In total, participants thus appraised each of the phrases once from each of the four possible perspectives [self (You), mom (Mom), best friend (Best), and classmates (Class)].

The complete task was administered during two fMRI runs (see Figure 1). Participants heard auditory stimuli through headphones (Resonance Technology, Northridge, CA) and responded yes or no to each phrase using a button box. Stimuli were presented and responses and reaction times were recorded using MacStim 3.2 (WhiteAnt Occasional Publishing, West Melbourne, VIC, Australia). Each run contained 8 blocks of 10 phrases (two sets of 10 unique phrases repeated four times each), resulting in a total of 160 phrases in 16 blocks. Each block lasted $46 \mathrm{~s}$ and consisted of an initial instruction cue lasting $6 \mathrm{~s}$ as well as 10 phrases, 1 phrase presented every $4 \mathrm{~s}$. Phrases were $1 \mathrm{~s}$ long and participants had $3 \mathrm{~s}$ to respond. Rest periods before and after each block lasted $12 \mathrm{~s}$. Each block contained 


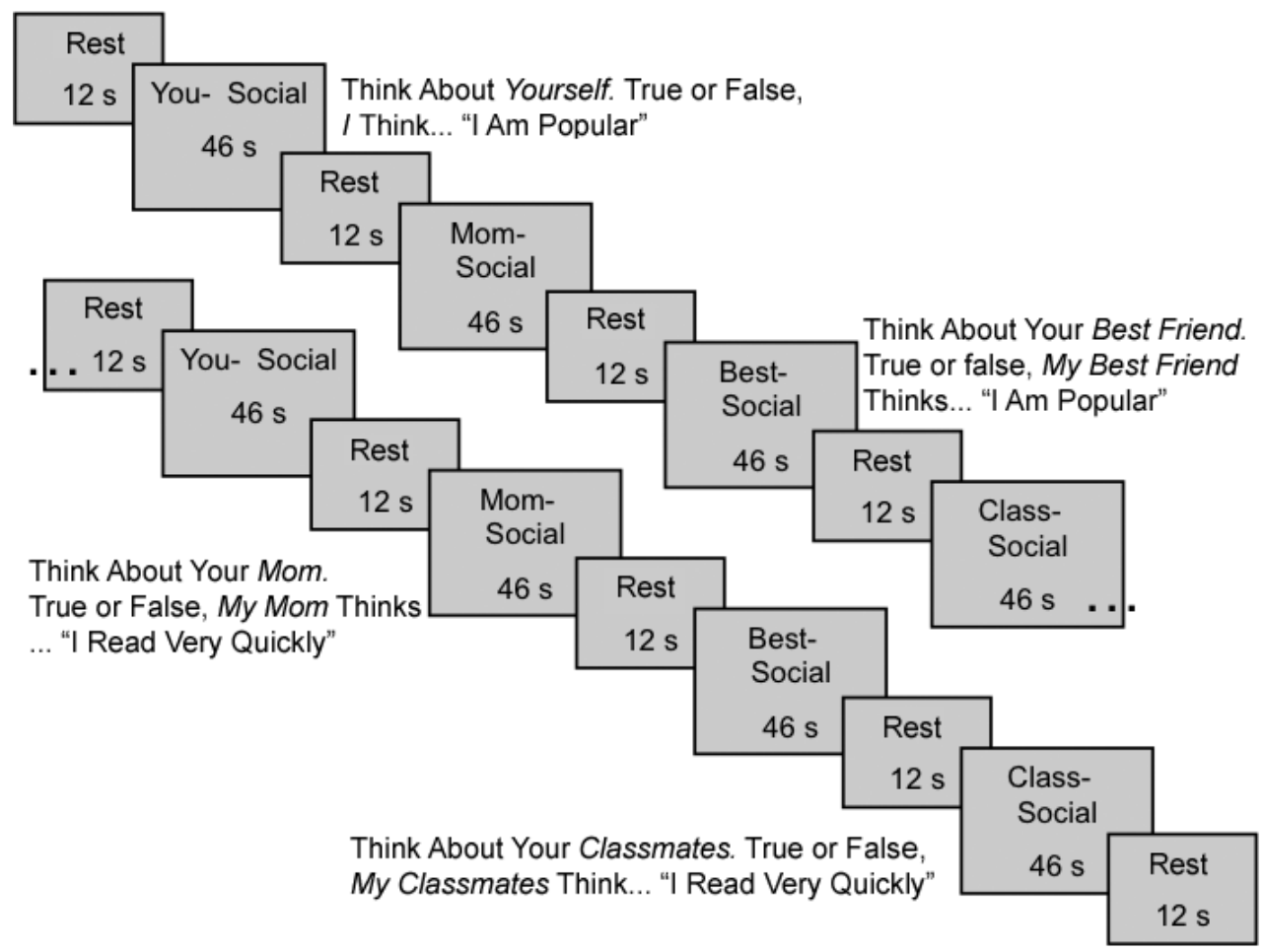

Figure 1. Task design. For each task block, participants heard a set of instructions reminding them whose perspective they were to take on themselves, followed by a series of 10 phrases. These stimuli included both positive and negative items (intermixed within blocks).

10 stimuli from either the social or academic domain, and valence of the stimuli was distributed equally within each series of 10 phrases so that each block included 5 positive and 5 negative stimuli relevant to the given domain. Because the same 10 stimuli were used in 4 consecutive blocks, each run contained a total of 4 blocks from the social domain and 4 blocks from the academic domain. Order of domains within runs and order of perspectives appraised within each set of 4 blocks were counterbalanced between participants using a Latin Square design.

Prior to the scan, participants were provided with extensive verbal instructions for the task. They were told to remember "it's always about you, just different people's opinion of you-your own, your mother's, your best friend's, and your classmates." Both adolescents and adults were instructed to think about their current behaviors at school when reporting about the phrases, and adults were specifically told to focus on their current experiences in graduate school, rather than relying on memories from childhood. When making reflected appraisals from the perspective of their best friend, adolescents were told to choose their best (same-gender) friend in their grade at school and to always think about the same person when making these appraisals, while adults were told to choose their best (same-gender) friend in their graduate school cohort. When making reflected appraisals from the perspective of their classmates, adolescents were told to think about their same-grade classmates when making these appraisals, while adults were told to think about the other students in their graduate school cohort. Due to computer malfunctions, behavioral data were not recorded for 2 adult and 2 adolescent participants. Both adults and adolescents showed considerable variation in their responses to the stimuli, both within each set of stimuli corresponding to a specific domain, as well as across perspectives when making reflected appraisals. That is, while participants tended to endorse positive items more than negative items, the specific items endorsed varied across participants (and to a lesser extent, within participants but across perspectives). This suggests that neither social desirability nor static ratings across perspectives drove participants' responses.

Following the scan, participants were asked a question tapping the degree to which the direct self-appraisals were answered intuitively: "Today when you were answering the questions about yourself, how much did you just know the 
answers"? Participants responded on a scale from 1 (not at all) to 5 (a lot). They were also asked to freely describe how they went about answering items in the reflected self-appraisal conditions. These data were not coded but suggested that participants used a combination of strategies to perform the task, including social perspective-taking as well as recall and integration of multiple relevant episodic memories. For example, adults reported "I thought about what other people think of me," "I kind of imagined them describing me to someone else and what they would say," "I was trying to put myself in their shoes and figure out how they would answer," and "I was trying to remember interactions we had had that they might think of, or things they might have said to me." Adolescents reported "Sometimes they just tell me, or you can figure out from what they are saying," "I based it on their personalities and what I think they would say," "I just looked at my self with another perspective," and "I thought about what they would think about me."

fMRI data acquisition. Images were acquired using a Siemens Allegra 3.0 Tesla head-only MRI (Erlangen, Germany) scanner. A 2-D spin-echo scout (repetition time $[\mathrm{TR}]=4,000 \mathrm{~ms}$, echo time [TE] $=40 \mathrm{~ms}$, matrix size $256 \times 256,4-\mathrm{mm}$ thick, 1-mm gap) was acquired in the sagittal plane to allow prescription of the slices to be obtained in the remaining scans. The entire appraisal task consisted of two functional scans, each lasting $7 \mathrm{~min} 56 \mathrm{~s}$, during each of which 238 images were acquired. These 238 images were collected over 33 axial slices covering the whole cerebral volume using a $\mathrm{T} 2 *$ weighted gradient-echo sequence ( $\mathrm{TR}=2,000 \mathrm{~ms}$, $\mathrm{TE}=30 \mathrm{~ms}$, flip angle $=90^{\circ}$, matrix size $64 \times 64$, field of view $[\mathrm{FOV}]=20 \mathrm{~cm} ; 3.125-\mathrm{mm}$ in-plane resolution, 4-mm thick, 1-mm gap). For each participant, a high-resolution structural echo-planar imaging volume was acquired coplanar with the functional scans $(\mathrm{TR}=5,000 \mathrm{~ms}, \mathrm{TE}=33 \mathrm{~ms}$, matrix size $128 \times 128$, FOV $=20 \mathrm{~cm}, 1.56-\mathrm{mm}$ inplane resolution, $3-\mathrm{mm}$ thick).

fMRI data analysis. Using Automated Image Registration (AIR 5.2.5; Woods, Grafton, Holmes, Cherry, \& Mazziotta, 1998; Woods, Grafton, Watson, Sicotte, \& Mazziotta, 1998) within the LONI pipeline environment (http://www.pipeline.loni. ucla.edu; Rex, Ma, \& Toga, 2003), all functional images for each participant were: (a) realigned to correct for head motion and coregistered to their respective high-resolution structural images using a six-parameter rigid-body transformation model, (b) spatially normalized into a Talairach-compatible atlas (Woods, Dapretto, Sicotte, Toga, \& Mazziotta, 1999) using polynominal nonlinear warping, and (c) smoothed using a 6-mm full-width, halfmaximum isotropic Gaussian kernel. Following image conversion and preprocessing, the imaging data were analyzed using Statistical Parametric Mapping (SPM; Wellcome Department of Cognitive Neurology, Institute of Neurology, London, UK; http://www.fil.ion.ucl.ac.uk/spm) and SPM toolboxes including MarsBaR, SnPM, and the WFU Pick Atlas. Importantly, there were no significant differences between age groups in amount of motion during runs (no participant evidenced greater than $2 \mathrm{~mm}$ of motion on average in either run), and all spatial normalizations were carefully examined to assure equal quality of data between age groups.

For each participant, condition effects were estimated according to the general linear model, using a canonical hemodynamic response function convolved with the block design described above, high-pass filtering to remove low-frequency noise, and an autoregressive model, AR(1), to estimate intrinsic autocorrelation of the data. The resulting contrast images were entered into second-level analyses using a random effects model to allow for inferences to be made at the population level (Friston, Holmes, Price, Buchel, \& Worsley, 1999). Comparisons between each condition and rest, direct comparisons between conditions within groups, and between-group comparisons of adolescents and adults were all corrected for multiple comparisons $(p<.05)$ across the entire brain volume at the level of spatial extent, and thresholded at $p<.005$ for magnitude. In these unmasked, whole-brain analyses, a minimum extent of 10 voxels was allowed only for clusters determined to be located in our a priori ROIs (MPFC, MPPC, TPJ, DMPFC, pSTS, temporal poles, orbitofrontal cortex, and insula); see Forman et al. (1995) for a discussion of joint thresholding procedures. To facilitate our interrogation of single-subject conjunction analyses and confirm our analyses of functionally derived clusters in a priori ROIs, we also constructed anatomical ROIs using the advanced module of the WFU Pick Atlas. This was accomplished via unions, intersections, and subtractions of relevant structures from the BAs putatively identified by the Talairach Daemon and the regions included in the Automated Anatomic Labeling atlas, so as to not rely exclusively on either definition. We confirmed that our functionally derived clusters were contained within our anatomical ROIs (in all cases, the latter were larger than the former) by viewing them 
simultaneously in MarsBaR. For display purposes, all images in the figures are thresholded at $p<.005$ for magnitude (uncorrected for multiple comparisons), with a minimum cluster extent of 10 voxels.

\section{Results}

\section{Behavioral Data}

Responses and reaction times were each entered into a repeated measures analysis of variance (ANOVA) having three within-subject factors-appraisal condition (source: You, Mom, Best, and Class), domain (social and academic), and valence (positive and negative) as well as one between-subject factor-age group (adolescents and adults). With respect to responses, there were main effects of source, $F(3,54)=4.98, p<.005$, and valence, $F(1,18)=174.47, p<.001$, which were qualified by the interaction between source and valence, $F(3,54)=4.31, p<.05$. Post hoc multiple comparisons indicated that while for positive items, participants answered "true" significantly more often in the Mom condition than when taking any other perspective on the self, there were no significant differences among conditions for negative items. With respect to reaction times, there were main effects of source, $F(3,54)=8.55, p<.001$; domain, $F(1,18)=10.24, p=.005$; and valence, $F(1$, 18) $=15.55, p=.001$, but no significant higher order interactions. Post hoc multiple comparisons indicated that latencies were significantly shorter in the You and Mom conditions (which did not differ from each other) than in the Best and Class conditions (which also did not differ from each other). Latencies were also significantly shorter in the social than the academic domain, as well as shorter for positive than negative items. In neither analysis were there any significant main effects of age group, nor were there any significant interactions with age group. Therefore at the behavioral level, no differences in the cognitive processes engaged by adolescents and adults during direct and reflected self-appraisals could be observed.

\section{fMRI-Interactions Between Appraisal Conditions and Age Group}

To investigate the similarities and differences among the neural systems supporting direct and reflected self-appraisals in adolescents and adults, we conducted three whole-brain, unmasked analyses testing our predicted interactions between age group and source (appraisal condition). The first two analyses addressed our first hypothesis, which was that direct self-appraisals would include more components of reflected self-appraisals in adolescents than adults. In these analyses, we did not consider differences among reflected appraisals types but rather averaged across taking the perspective of mothers, best friends, and classmates on the self. The third analysis examined our second hypothesis that we would replicate our previous work, in which a child sample engaged MPFC more during direct self-knowledge retrieval (relative to a resting baseline) than did adults.

We first conducted a two-sample $t$ test of the contrast comparing what was more active during direct self-appraisals than reflected self-appraisals in adolescents versus adults, that is, Adolescent $($ You $>($ Mom, Best, Class) $)>$ Adult (You > (Mom, Best, Class)). In other words, this analysis represented a full crossover interaction between age group (adolescent or adult) and self-appraisal type (direct or reflected). This analysis identified several prefrontal clusters (see Figure 2A): MPFC (BA 10 $[14,66,4] t=3.29$ and BA $9 / 10[-45028] t=3.64)$, DMPFC (BA 9 [-8 46 36] $t=3.50$ ), the left frontal pole (BA $10\left[\begin{array}{lll}-26 & 60 & 2\end{array}\right] t=3.11$ ), and anterior cingulate cortex (ACC) including both rostral and dorsal anterior cingulate (BA 32 [10 40 22] $t=3.20$ and [-2 32 32] $t=3.11)$. To decompose this interaction, parameter estimates (mean levels of BOLD signal) were extracted from these clusters during direct and reflected appraisals in adolescents and in adults. The results demonstrated that these effects were generally caused by greater recruitment of these regions during direct self-appraisals in adolescents, relative to all other conditions, as well as a trend toward enhanced activity in these regions during adult and/or adolescent reflected selfappraisals, relative to adult direct self-appraisals (see Figure 2B). The reverse contrast-that is Adult (You > Mom, Best, Class) $>$ Adolescent (You > Mom, Best, Class)—did not result in any significant clusters of activation. When an equivalent analysis was conducted using an ANOVA with one between-subjects factor (age group: adolescent and adult) and one within-subjects factor (source: You, Mom, Best, and Class), a virtually identical pattern of results was obtained. Post hoc permutation analyses conducted in SnPM confirmed the significance of the clusters of activation in MPFC (BA 10 [10 66 4] $t=3.32$ and BA $9 / 10$ [-4 50 28] $t=3.53$ ), DMPFC (BA 9 [-6 4636$] t=3.03$ ), and ACC (BA 24 [-2 30 30] $t=3.61$, and BA 32 [10 36 20] $t=2.97$ ), given our data and experimental design. We also conducted a specific permutation analysis that replaced 

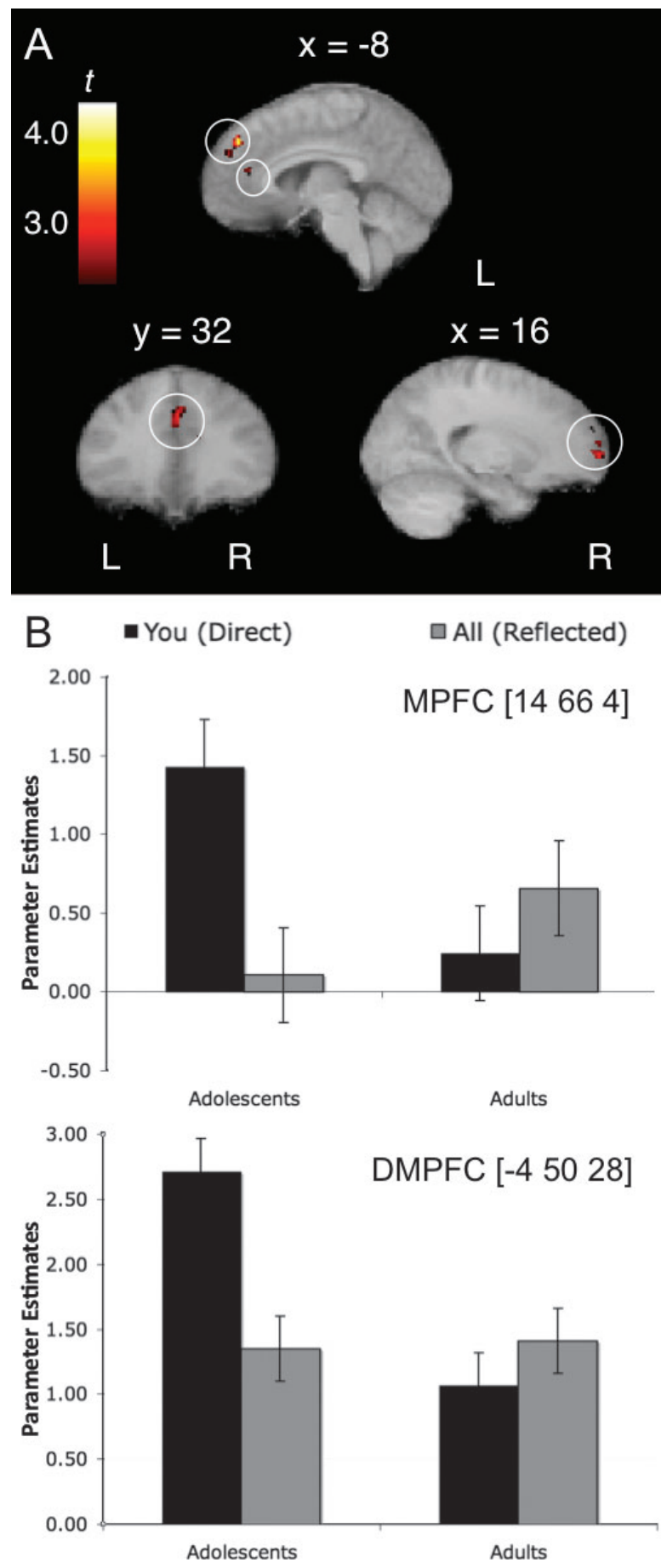

Figure 2. Full crossover interaction between appraisal source (direct or reflected) and age (adolescent or adult). Panel A illustrates activity in medial and dorsomedial prefrontal cortex (MPFC and DMPFC) and anterior cingulate cortex that was relatively greater in the crossover interaction capturing regions that were differentially active during direct and reflected selfappraisals in children versus adults. Panel B depicts mean activity in MPFC and DMPFC, demonstrating that these regions were generally more active in direct than reflected appraisals in adolescents, and vice versa in adults to a lesser extent. age with gender, and produced only one significant result: MPPC (BA 7 [ $-4-6432] t=3.42$ ) was more active during direct than reflected self-appraisals in females compared with males. This suggests age was a more relevant dimension in this analysis than gender.

Next, we entered an alternative contrast into this ANOVA with one between-subjects factor (age group: adolescent and adult) and one within-subjects factor (source: You, Mom, Best, and Class). This interaction term identified which regions were equally active among adult reflected self-appraisals and all adolescent appraisals, more so than during adult direct self-appraisals, that is, ((Adolescent (You, Mom, Best, Class) = Adult (Mom, Best, Class) > Adult (You)). In other words, this contrast was built to identify regions that were less active in particular during adult direct self-appraisals, compared with all other conditions. This interaction analysis produced only two significant results across the entire brain volume (see Figure $3 \mathrm{~A}$ ): MPPC (BA 31 [-8 -40 30] $t=3.09$ ) and a cluster in the region of left TPJ (BA 39/22 [ $\left.\begin{array}{lll}-44 & -60 & 36\end{array}\right]$ $t=2.85$ ). To decompose this interaction, parameter estimates (mean levels of BOLD signal) were extracted from these clusters during direct and reflected self-appraisals in adolescents and in adults. The results demonstrated that these effects were generally caused by greater recruitment of these regions during all conditions relative to direct self-appraisals in adults (see Figure 3B). The reverse contrast - that is, Adult (You) $>$ (Adult (Mom, Best, Class $)=$ Adolescent $($ You, Mom, Best, Class) $)$-did not result in any significant clusters of activation. The appropriate post hoc permutation analyses could not be conducted in SnPM. However, we again conducted a specific permutation analysis that replaced age with gender. This produced no significant results in either direction, suggesting age is a much more relevant dimension for this contrast than gender.

Finally, we conducted a two-sample $t$ test on the contrast comparing what was more active during direct self-appraisals than a resting baseline in adolescents and adults, that is, Adolescent (You) > Adult (You). In line with our second hypothesis and replicating our previous work (Pfeifer et al., 2007), we observed that during direct self-appraisals relative to a resting baseline, adolescents activated several regions more than adults, including (see Figure 4): ACC (BA 32 [4 30 36] $t=5.57$ ), MPFC (BA 10 [12 64 2] $\left.t=4.11\left[\begin{array}{lll}-12 & 62 & 14\end{array}\right] t=3.25\right)$ extending into DMPFC (BA 9 [4 50 32] $t=3.32$ ), 


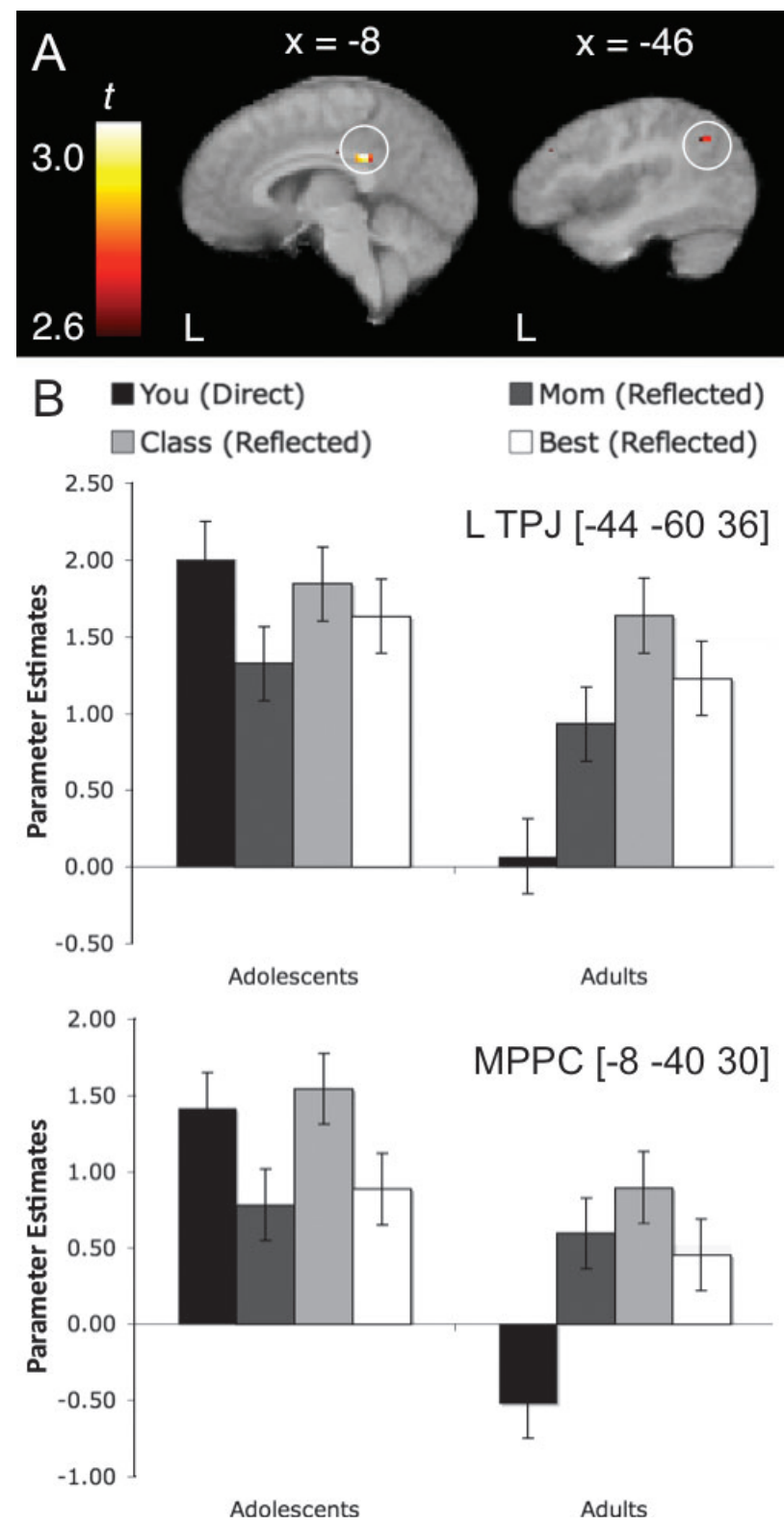

Figure 3. Regions commonly activated by all conditions except direct self-appraisals in adults. Panel A illustrates activity in medial posterior parietal cortex (MPPC) and left temporalparietal junction (L TPJ) that was relatively greater in the interaction identifying regions that were active during all appraisal conditions except direct self-appraisals in adults. Panel $\mathrm{B}$ depicts mean activity in these two regions, demonstrating that these regions were indeed more active in all appraisals in adolescents and reflected self-appraisals in adults, when compared with direct self-appraisals in adults.

and MPPC (posterior cingulate in BA $31[-8-40$ 30] $t=3.70$ ). Furthermore, there was also greater activity for adolescents than adults during direct self-appraisals in an inferior parietal region including left TPJ (BA 39/22 [-54 -62 26] $t=3.42)$ as well

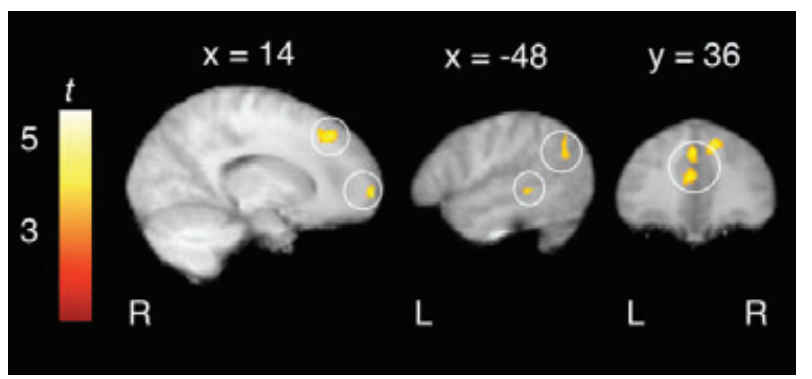

Figure 4. Regions more active during direct self-appraisals in adolescents than in adults. Medial and dorsomedial prefrontal cortex, posterior superior temporal sulcus, left temporal-parietal junction, and anterior cingulate cortex were all more active during direct self-appraisals in adolescents than in adults.

as in pSTS (BA $22\left[\begin{array}{lll}-48 & -38 & 2\end{array}\right]=3.44$ ), a pattern that was not observed in our previous study of children who were approximately 2.5 years younger on average (9.5-10.8 years old, $M=10.2$ years) than the adolescent sample in the current study (11.3-13.7 years old, $M=12.7$ years). The reverse contrast — that is, Adult (You) $>$ Adolescent (You) did not result in any significant clusters of activation. Post hoc permutation analyses conducted in SnPM confirmed the significance of the clusters of activation in MPFC (BA 10 [10 66 2] $t=4.03$ ), DMPFC (BA 9 [-4 50 30] $t=3.79$ ); right frontal pole (BA 10 [18 50 34] $t=3.92)$, ACC (BA 32/24 [-2 30 34] $t=4.85$ ); and left TPJ (BA 39/22 [-54 -62 26] $t=3.38$ ), given our data and experimental design. We also conducted a specific permutation analysis that replaced age with gender, and produced only one significant result: MPPC (BA 7 [ [ 2 -48 48] $t=3.63$ ) was more active during direct than reflected self-appraisals in females compared with males. As before, this suggests age was a much more relevant dimension in this analysis than gender.

To confirm our interpretations of the clusters resulting from these interaction analyses, we also conducted post hoc analyses in the anatomical a priori ROIs we defined using the advanced module of the WFU Pick Atlas (for more details refer to the Method section). Mean parameter estimates for each participant during direct and reflected selfappraisals versus rest were extracted from these ROIs and compared using ANOVAs and two-sample $t$ test. Unfortunately, due to the substantially larger volume of these ROIs relative to the clusters observed in our interaction analyses, very few significant differences were observed. The results we observed above in our interaction analyses for DMPFC and MPFC generalized across the entire 
anatomical region. That is, whether the functionally derived cluster or anatomical ROI was interrogated, adolescents engaged MPFC and DMPFC significantly more during direct than reflected self-appraisals, in comparison to adults; and adolescents likewise engaged these regions during direct self-appraisals relative to a resting baseline more than did adults. On the other hand, the results in MPPC and TPJ did not generalize across the entire anatomical ROI we defined. However, the patterns of means in MPPC and TPJ were consistent with the interaction effects reported above.

\section{fMRI-Supplementary Analyses of Appraisal Conditions}

To further interrogate the interaction analyses between age group and condition (source) reported above, we describe next supplementary analyses that examine each appraisal condition separately, relative to a resting baseline, in each age group, as well as conjunction analyses conducted across conditions in each age group and in single subject data. Each conjunction analysis tested against the conjunction null (and not the intermediate or global null; see Friston, Penny, \& Glaser, 2005; Nichols, Brett, Andersson, Wager, \& Poline, 2005), in other words identifying voxels that were significantly active in each appraisal condition individually (You AND Mom AND Best AND Class). There were no main effects of domain for adolescents or adults, as demonstrated by a one-sample $t$ test (Social vs. Academic) conducted separately in each age group.

Adults. A conjunction analysis identified common activations in bilateral superior temporal cortex, left inferior frontal gyrus, primary motor/ premotor cortex, DMPFC and MPFC, and the frontal poles, MPPC, caudate, putamen, thalamus, and cerebellum. See Table 1 and Figure 5 for results from a one-sample $t$ test conducted on each appraisal condition (You, Mom, Best, and Class) in comparison to rest. An ANOVA with one withinsubject factor (source: You, Mom, Best, and Class) demonstrated that no regions were significantly more active during direct than reflected selfappraisals. In contrast, three regions were significantly more active on average across all three reflected perspectives compared to during direct self-appraisals: MPPC (BA 23/31 [-6, -34, 28], $t=3.97)$, the left frontal pole extending medially into MPFC (BA 10 [-24 64 0], $t=3.76$ ), and left TPJ at the intersection of the posterior superior temporal, angular, and supramarginal gyri (BA 40 [-42, $-60,38], t=3.57)$.
Adolescents. As in adults, a conjunction analysis identified common activations in bilateral superior temporal cortex, left inferior frontal gyrus, primary motor/premotor cortex, DMPFC and MPFC, and the frontal poles, MPPC, caudate, putamen, thalamus, and cerebellum. See Table 2 and Figure 6 for results from a one-sample $t$ test conducted on each appraisal condition (You, Mom, Best, and Class) in comparison to rest. However, only in adolescents did the conjunction analysis also identify significant activity in left TPJ at the intersection of the posterior superior temporal, angular, and supramarginal gyri. An ANOVA with one within-subject factor (source: You, Mom, Best, and Class) demonstrated that, contrary to the findings in adults, no regions were significantly more active during reflected than direct self-appraisals, and neither were any regions significantly more active during direct than reflected self-appraisals at our statistical thresholds.

Post hoc correlations in left TPJ. To interrogate further the pattern of results observed in left TPJ, a region engaged during direct self-appraisals in adolescents but not adults, parameter estimates (mean levels of BOLD signal for each participant) were extracted from this cluster and correlated with various behavioral measures of interest that were available for most adolescent participants. Importantly, we observed that the activity in left TPJ during direct self-appraisals was unrelated to verbal IQ, $r(6)=-.099, n s$; reaction times during that condition, $r(8)=0.115$, $n s ;$ or age, $r(10)=.238$, ns. However, we observed a marginally significant association with the question asked of them following the scan tapping the intuitive nature of their responses (how much did you just know the answers?): Specifically, to the extent adolescents reported that direct self-appraisals felt intuitive, less activity was observed in the left TPJ, $r(10)=-0.469, p=.062$.

Single subject overlap analyses. We also conducted conjunction analyses at the individual subject level, which tested for significant overlap in our a priori ROIs during all four appraisal conditions in each subject (against the conjunction null). In these analyses only, we used a mask that included just our eight ROIs, constructed in a way that was anatomically/functionally independent from our study data using the advanced module of the WFU Pick Atlas (for more details, refer to the Method section). A minimum of 8 of 12 participants in each age group evidenced statistically significant activation in all of our ROIs during each appraisal condition, except in TPJ (4 of 12 
Table 1

Regions Activated During Each Appraisal Condition Versus Rest in Adults

\begin{tabular}{|c|c|c|c|c|c|c|c|c|c|c|c|c|c|c|c|c|c|c|}
\hline \multirow[b]{2}{*}{ Anatomical region } & \multirow[b]{2}{*}{ BA } & \multirow[b]{2}{*}{ Hemisphere } & \multicolumn{4}{|c|}{ You-rest } & \multicolumn{4}{|c|}{ Mom-rest } & \multicolumn{4}{|c|}{ Best-rest } & \multicolumn{4}{|c|}{ Class-rest } \\
\hline & & & $x$ & $y$ & $z$ & $t$ & $x$ & $y$ & $z$ & $t$ & $x$ & $y$ & $z$ & $t$ & $x$ & $y$ & $z$ & $t$ \\
\hline \multirow[t]{2}{*}{ Superior temporal } & 22 & $\mathrm{~L}$ & -60 & -16 & -4 & 11.21 & -60 & -6 & -4 & 13.59 & -58 & -28 & 0 & 6.11 & -56 & -30 & 0 & 11.56 \\
\hline & & $\mathrm{R}$ & 60 & -14 & -2 & 12.83 & 50 & -14 & 2 & 12.63 & 60 & -14 & -2 & 6.68 & 50 & -14 & 2 & 8.06 \\
\hline \multirow[t]{2}{*}{ Medial temporal } & 21 & $\mathrm{~L}$ & -48 & -6 & -20 & 8.34 & -52 & 2 & -16 & 12.52 & -66 & -20 & -12 & 5.10 & -54 & 4 & -14 & 5.86 \\
\hline & & $\mathrm{R}$ & 50 & -32 & 2 & 11.03 & 48 & -32 & 4 & 12.31 & 52 & -24 & -8 & 4.58 & & & & \\
\hline \multirow{2}{*}{$\begin{array}{l}\text { Primary/secondary } \\
\text { auditory }\end{array}$} & $41 / 42$ & $\mathrm{~L}$ & -56 & -24 & 8 & 8.43 & -60 & -24 & 10 & 8.61 & -60 & -32 & 6 & 4.32 & -48 & -26 & 6 & 6.08 \\
\hline & $41 / 42$ & $\mathrm{R}$ & 42 & -22 & 10 & 5.48 & 44 & -16 & 8 & 8.24 & 40 & -20 & 10 & 8.29 & 40 & -20 & 10 & 7.33 \\
\hline \multirow[t]{2}{*}{ Temporal pole } & 38 & $\mathrm{~L}$ & -46 & 12 & -22 & 5.63 & -44 & 2 & -26 & 7.57 & -48 & 6 & -30 & 4.94 & -46 & 4 & -30 & 6.20 \\
\hline & & $\mathrm{R}$ & 38 & 12 & -26 & 7.87 & 40 & 12 & -28 & 5.92 & & & & & & & & \\
\hline \multirow[t]{5}{*}{ Inferior frontal } & 47 & $\mathrm{~L}$ & -46 & 22 & -4 & 7.10 & -46 & 18 & -4 & 9.28 & -46 & 24 & 0 & 4.51 & -42 & 26 & 0 & 5.54 \\
\hline & & $\mathrm{R}$ & 42 & 26 & -8 & 5.03 & 40 & 26 & -8 & 5.71 & & & & & 48 & 22 & -2 & 4.06 \\
\hline & 45 & $\mathrm{~L}$ & -56 & 22 & 8 & 6.37 & -54 & 26 & 10 & 6.56 & -56 & 26 & 6 & 8.41 & -56 & 26 & 6 & 10.88 \\
\hline & & $\mathrm{R}$ & & & & & & & & & & & & & & & & \\
\hline & $44 / 45$ & $\mathrm{~L}$ & -54 & 10 & 10 & 5.84 & -54 & 18 & 12 & 5.28 & -56 & 20 & 6 & 7.97 & -50 & 18 & 4 & 6.34 \\
\hline \multirow[t]{2}{*}{ MPFC } & 10 & & -2 & 58 & 10 & 6.19 & 14 & 50 & 12 & 4.84 & 2 & 54 & 10 & 4.74 & & & & \\
\hline & $9 / 10$ & & -6 & 54 & 28 & 6.40 & -10 & 50 & 26 & 6.04 & -10 & 42 & 26 & 3.17 & -6 & 54 & 28 & 7.46 \\
\hline \multirow[t]{2}{*}{ DMPFC } & $8 / 9$ & & 10 & 40 & 48 & 6.78 & 6 & 42 & 36 & 5.30 & -8 & 50 & 34 & 10.46 & -10 & 36 & 48 & 6.97 \\
\hline & $6 / 8$ & & -6 & 16 & 50 & 8.97 & -6 & 14 & 50 & 8.88 & -6 & 24 & 56 & 7.74 & -12 & 12 & 52 & 9.02 \\
\hline ACC & 32 & & & & & & -2 & 32 & 30 & 5.20 & 4 & 20 & 36 & 3.74 & 4 & 20 & 34 & 5.25 \\
\hline MPPC & $7 / 31$ & & -14 & -58 & 36 & 5.20 & -10 & -52 & 34 & 8.45 & -8 & -58 & 30 & 6.95 & -16 & -60 & 38 & 4.97 \\
\hline \multirow[t]{2}{*}{ TPJ } & $39 / 40 / 22$ & $\mathrm{~L}$ & & & & & -48 & -64 & 36 & 4.33 & -50 & -56 & 36 & 5.10 & -48 & -58 & 40 & 5.06 \\
\hline & $39 / 40 / 22$ & $\mathrm{R}$ & & & & & 40 & -56 & 36 & 5.41 & & & & & & & & \\
\hline $\begin{array}{l}\text { Inferior parietal } \\
\text { lobule }\end{array}$ & 40 & $\mathrm{~L}$ & -58 & -20 & 34 & 6.35 & & & & & -50 & -28 & 44 & 4.69 & -52 & -34 & 40 & 5.21 \\
\hline \multirow[t]{2}{*}{ Insula } & & $\mathrm{L}$ & -34 & 20 & 0 & 5.56 & -36 & 22 & -4 & 8.32 & -34 & 2 & 0 & 6.25 & -32 & 4 & 0 & 5.11 \\
\hline & & & & & & & 30 & 16 & -6 & 5.09 & & & & & 34 & 24 & 2 & 3.42 \\
\hline \multirow[t]{2}{*}{ Putamen } & & $\mathrm{L}$ & -24 & 8 & 14 & 8.02 & -20 & 6 & 16 & 10.39 & -22 & 10 & 12 & 6.52 & -20 & 12 & 6 & 4.88 \\
\hline & & $\mathrm{R}$ & & & & & 14 & 6 & -4 & 6.47 & & & & & & & & \\
\hline Thalamus & & $\mathrm{L}$ & -12 & -4 & 6 & 4.78 & -10 & -4 & 6 & 5.61 & & & & & & & & \\
\hline \multirow[t]{2}{*}{ Caudate } & & $\mathrm{L}$ & -12 & -2 & 16 & 4.51 & & & & & & & & & & & & \\
\hline & & $\mathrm{R}$ & 14 & 4 & 12 & 5.22 & 16 & 8 & 8 & 6.39 & 12 & 12 & 12 & 4.97 & 14 & 14 & 6 & 5.42 \\
\hline Premotor cortex & 6 & $\mathrm{~L}$ & -46 & 2 & 48 & 7.83 & -44 & 4 & 50 & 5.75 & -42 & 2 & 52 & 5.47 & -42 & 6 & 52 & 5.03 \\
\hline Primary motor cortex & 4 & $\mathrm{~L}$ & -34 & -14 & 60 & 7.69 & -42 & -14 & 58 & 5.48 & -38 & -18 & 56 & 5.84 & -24 & -14 & 50 & 4.80 \\
\hline Cerebellum & & & -28 & -62 & -16 & 7.24 & 28 & -70 & -22 & 13.02 & 26 & -72 & -22 & 4.97 & 30 & -70 & -22 & 6.57 \\
\hline
\end{tabular}

Note. $\mathrm{BA}=$ Brodmann's area; $\mathrm{L}$ and $\mathrm{R}=$ left and right hemispheres; $x, \mathrm{y}$, and $\mathrm{z}=$ left-right, anterior-posterior, and inferior-superior dimensions, respectively; $t=t$ score at those coordinates (local maxima or submaxima); MPFC = medial prefrontal cortex; $\mathrm{DMPFC}=$ dorsal MPFC; $\mathrm{ACC}=$ anterior cingulate cortex; $\mathrm{MPPC}=$ medial posterior parietal cortex; $\mathrm{TPJ}=$ temporal-parietal junction .

participants for adults vs. 9 of 12 participants for adolescents).

\section{fMRI-Interactions Between Sources and Domains in Adolescents}

Finally, we wanted to explore whether the domain of self-concept and source of reflected selfappraisal impacted the patterns we observed in our early adolescent sample, as our third hypothesis predicted. In particular, we aimed to contrast patterns of activity when the source of reflected self-appraisal was most relevant to the self-concept domain according to previous developmental research summarized in the Introduction-that is, we hoped to identify which regions were relatively more engaged in adolescents when the domain and source "matched" (i.e., Mom-Academic and BestSocial) versus when they did not (i.e., Mom-Social and Best-Academic). In this whole-brain, unmasked analysis, the contrast of interest-i.e., (Mom-Academic + Best-Social) $>$ (Mom-Social + Best-Academic) demonstrated that activity was significantly modulated by reflected self-appraisals exhibiting a "match" across source and domain in only two regions: MPPC (BA 31 [14 -46 32] $t=3.24$ ) and 


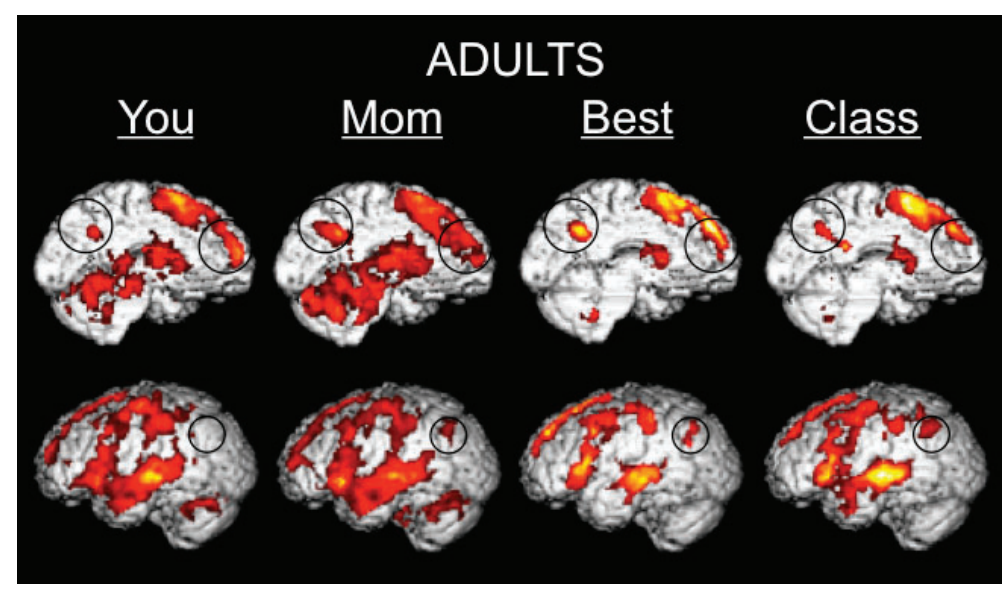

Figure 5. Comparison of all appraisal conditions and rest in adults. Images depict activation in adults during direct selfappraisals (You) and reflected self-appraisals from three perspectives—mother (Mom), best friend (Best), and classmates (Class)—in comparison to a resting baseline. Medial prefrontal cortex, medial posterior parietal cortex, and left temporal-parietal junction are encircled.

MPFC (BA 10 [18 48 24] $t=3.21$ ). The first cluster has subpeaks extending medially including at [4 $\left.\begin{array}{ll}-46 & 34\end{array}\right]$, and the second cluster has subpeaks extending in medial, anterior, and inferior directions including at [12 52 16]. As shown in Figure 7, which extracts parameter estimates (mean levels of BOLD signal) from these clusters, there was more activity in both these regions when the reflected self-appraisals were made in domains that were relevant to an evaluative source's sphere of influence, and essentially no significant activity in those regions on average when there was not a match between domain and source. The reverse contrast-i.e., (Mom-Social + Best-Academic) > (Mom-Academic + Best-Social) - did not result in any significant clusters of activation.

\section{Discussion}

The goals of this study were to (a) examine the neural correlates of direct and reflected self-appraisals, comparing between an adult sample and an adolescent sample and (b) explore the influence of evaluative sources across domains on the reflected appraisal process at a neural level, in our adolescent sample only. Converging results across a number of analyses suggest the possibility that, as hypothesized, direct self-reflection in teenagers incorporates aspects of reflected appraisal processes. Even when adolescents were not instructed to think about other people's perspectives on the self, they engaged components of the social perception network commonly associated with doing so (including TPJ, DMPFC, and pSTS), in addition to recruiting the medial fronto-parietal network for self-reflection and self-knowledge retrieval (in MPFC and MPPC). Furthermore, activity in both self- and social-perception networks was more intense during direct self-appraisals in adolescents than in adults, replicating and extending our previous work (Pfeifer et al., 2007). We additionally observed that when an evaluative source of selfknowledge matched the domain of self-concept (that is, taking a mother's perspective on the academic self or a best friend's perspective on the social self), there was relatively greater activity in MPFC and MPPC. These results raise two intriguing hypotheses for discussion and future study: (a) consistent with symbolic interactionism and lay theories about adolescent self-development, asking teenagers in particular to reflect on the self directly or retrieve self-knowledge may commonly induce spontaneous assessments of what others (including family members or peers) think of them, and (b) reflected self-appraisals made in a domain where a given evaluative source possesses relatively greater influence may be tagged by the brain as more selfrelevant.

Pertaining to the first hypothesis, there are competing developmental explanations for why direct self-appraisals seem to display characteristics of reflected self-appraisals in early adolescence. One possibility is that for a variety of social and cognitive reasons, self-appraisals become much more contingent on what individuals believe others think about the self specifically during adolescence in comparison to either adulthood (as shown in this study) or childhood (as suggested by our previous work; Pfeifer et al., 2007). In our prior study using 
Table 2

Regions Activated During Each Appraisal Condition Versus Rest in Adolescents

\begin{tabular}{|c|c|c|c|c|c|c|c|c|c|c|c|c|c|c|c|c|c|c|}
\hline \multirow[b]{2}{*}{ Anatomical region } & \multirow[b]{2}{*}{ BA } & \multirow[b]{2}{*}{ Hemisphere } & \multicolumn{4}{|c|}{ You-rest } & \multicolumn{4}{|c|}{ Mom-rest } & \multicolumn{4}{|c|}{ Best-rest } & \multicolumn{4}{|c|}{ Class-rest } \\
\hline & & & $x$ & $y$ & $z$ & $t$ & $x$ & $y$ & $z$ & $t$ & $x$ & $y$ & $z$ & $t$ & $x$ & $y$ & $z$ & $t$ \\
\hline \multirow[t]{2}{*}{ Superior temporal } & 22 & $\mathrm{~L}$ & -64 & -18 & 0 & 8.78 & -62 & -26 & 2 & 7.30 & -62 & -18 & 2 & 10.85 & -58 & -24 & 0 & 13.33 \\
\hline & & $\mathrm{R}$ & 56 & -10 & 2 & 18.41 & 58 & -10 & -2 & 4.02 & 52 & -30 & 6 & 9.10 & 56 & -16 & -2 & 8.61 \\
\hline \multirow{2}{*}{ Medial temporal } & 21 & $\mathrm{~L}$ & -56 & -34 & 2 & 7.23 & -54 & -32 & 0 & 5.60 & -62 & -26 & 2 & 9.83 & -62 & -32 & 0 & 7.66 \\
\hline & & $\mathrm{R}$ & 58 & -20 & -12 & 3.26 & 50 & -24 & -6 & 3.21 & 58 & -20 & -12 & 4.76 & 62 & -34 & 4 & 7.07 \\
\hline \multirow{2}{*}{$\begin{array}{l}\text { Primary/secondary } \\
\text { auditory }\end{array}$} & $41 / 42$ & $\mathrm{~L}$ & & & & & -54 & -8 & -10 & 3.97 & -46 & -28 & 10 & 5.84 & -44 & -28 & 10 & 4.95 \\
\hline & $41 / 42$ & $\mathrm{R}$ & 36 & -34 & 10 & 5.55 & 50 & -18 & 4 & 4.53 & & & & & & & & \\
\hline \multirow[t]{2}{*}{ Temporal pole } & 38 & $\mathrm{~L}$ & -42 & 18 & -14 & 5.20 & & & & & & & & & & & & \\
\hline & & $\mathrm{R}$ & & & & & & & & & & & & & & & & \\
\hline \multirow[t]{5}{*}{ Inferior frontal } & 47 & $\mathrm{~L}$ & -54 & 24 & 0 & 9.58 & -50 & 24 & -4 & 5.04 & -50 & 18 & -4 & 8.00 & -46 & 22 & -4 & 7.18 \\
\hline & & $\mathrm{R}$ & 42 & 24 & -8 & 6.26 & & & & & & & & & & & & \\
\hline & 45 & $\mathrm{~L}$ & -58 & 24 & 12 & 7.53 & -56 & 24 & 14 & 4.22 & -54 & 18 & 20 & 6.89 & -56 & 26 & 12 & 7.49 \\
\hline & & $\mathrm{R}$ & 52 & 20 & 2 & 4.29 & & & & & & & & & & & & \\
\hline & $44 / 45$ & $\mathrm{~L}$ & -48 & 10 & 16 & 3.62 & & & & & -50 & 14 & 2 & 5.69 & -56 & 20 & 22 & 5.86 \\
\hline \multirow[t]{2}{*}{ MPFC } & 10 & & -14 & 62 & 16 & 7.59 & -6 & 62 & 4 & 3.88 & -10 & 64 & 18 & 7.32 & 2 & 56 & 20 & 4.54 \\
\hline & $9 / 10$ & & -8 & 52 & 28 & 7.34 & -8 & 50 & 28 & 3.89 & -8 & 50 & 32 & 6.29 & -6 & 50 & 30 & 4.10 \\
\hline \multirow[t]{2}{*}{ DMPFC } & $8 / 9$ & & -8 & 46 & 40 & 7.68 & -10 & 46 & 42 & 5.32 & -8 & 42 & 42 & 4.10 & & & & \\
\hline & $6 / 8$ & & -6 & 24 & 50 & 6.88 & -8 & 26 & 56 & 7.93 & -4 & 22 & 52 & 8.37 & -8 & 24 & 52 & 6.91 \\
\hline ACC & 32 & & 6 & 30 & 36 & 8.46 & 8 & 30 & 28 & 4.06 & -8 & 16 & 42 & 7.46 & -8 & 34 & 20 & 5.70 \\
\hline MPPC & $7 / 31$ & & -8 & -52 & 40 & 5.46 & -10 & -50 & 28 & 4.02 & -4 & -60 & 38 & 5.89 & -4 & -58 & 36 & 6.16 \\
\hline \multirow{2}{*}{ TPJ } & $39 / 40 / 22$ & $\mathrm{~L}$ & -60 & -62 & 24 & 5.47 & -54 & -54 & 26 & 5.51 & -54 & -46 & 26 & 4.87 & -50 & -60 & 20 & 4.21 \\
\hline & $39 / 40 / 22$ & $\mathrm{R}$ & & & & & & & & & & & & & & & & \\
\hline $\begin{array}{l}\text { Inferior parietal } \\
\text { lobule }\end{array}$ & 40 & $\mathrm{~L}$ & -48 & -24 & 50 & 6.55 & & & & & -50 & -36 & 48 & 3.74 & -44 & -28 & 48 & 6.28 \\
\hline Insula & & $\mathrm{L}$ & -32 & 18 & -6 & 4.00 & & & & & -30 & 6 & -8 & 4.40 & & & & \\
\hline \multirow[t]{2}{*}{ Putamen } & & $\mathrm{L}$ & -20 & 12 & 8 & 5.71 & & & & & -20 & 0 & 10 & 4.96 & -20 & 12 & 2 & 5.84 \\
\hline & & $\mathrm{R}$ & & & & & & & & & & & & & & & & \\
\hline Thalamus & & $\mathrm{L}$ & -4 & -2 & 10 & 6.20 & & & & & -10 & -12 & 14 & 5.91 & -16 & -16 & 4 & 4.52 \\
\hline \multirow[t]{2}{*}{ Caudate } & & $\mathrm{L}$ & & & & & & & & & -10 & 8 & 16 & 8.58 & & & & \\
\hline & & $\mathrm{R}$ & & & & & & & & & & & & & & & & \\
\hline Premotor cortex & 6 & $\mathrm{~L}$ & -44 & 4 & 46 & 6.78 & -40 & 4 & 54 & 4.39 & -46 & 4 & 42 & 10.16 & -48 & 4 & 46 & 5.61 \\
\hline Primary motor cortex & 4 & $\mathrm{~L}$ & & & & & & & & & -38 & -22 & 60 & 4.09 & -36 & -24 & 62 & 5.05 \\
\hline Cerebellum & & & 30 & -64 & -26 & 9.79 & 22 & -46 & -26 & 6.34 & 20 & -50 & -22 & 6.98 & 24 & -72 & -20 & 7.16 \\
\hline
\end{tabular}

Note. $\mathrm{BA}=$ Brodmann's area; $\mathrm{L}$ and $\mathrm{R}=$ left and right hemispheres; $x, y$, and $z=$ left-right, anterior-posterior, and inferior-superior dimensions, respectively; $t=t$ score at those coordinates (local maxima or submaxima); MPFC = medial prefrontal cortex; $\mathrm{DMPFC}=$ dorsal MPFC; $\mathrm{ACC}=$ anterior cingulate cortex; $\mathrm{MPPC}=$ medial posterior parietal cortex; $\mathrm{TPJ}=$ temporal-parietal junction .

9- to 10-year-old children and nearly identical stimuli, we observed activity in MPFC during direct self-appraisals versus rest, but not in MPPC or TPJ. However, the children were not instructed to engage in reflected self-appraisals; in some task blocks they reported whether the phrases were selfdescriptive, and in others whether they described Harry Potter. Therefore, a second possibility is that perhaps simply due to the experimental design, once given the idea to make reflected self-appraisals, younger samples (children and adolescents alike) cannot inhibit the simultaneous process of considering others' opinions of themselves. More generally, adolescents (and thus children) may be less good at following task directions than adults and accidentally incorporate the perspective of others during direct self-appraisals. Future research should attempt to test these possibilities directly.

Regarding the second hypothesis, two neuroimaging studies have already demonstrated that the contextual domain in which appraisals are made influences self-processing (Lieberman et al., 2004; Rameson \& Lieberman, 2007). However, this is the first study to examine whether taking the perspective of a person who is specifically relevant to evaluating one's attributes and abilities in a given domain affects the neural processing of selfrelevant information as well. That is, we queried 


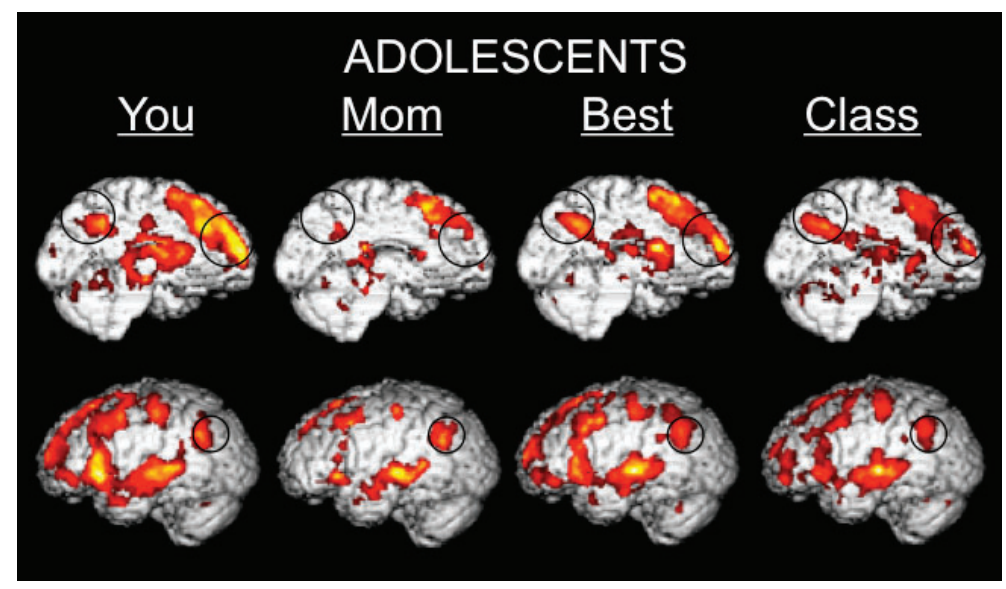

Figure 6. Comparison of all appraisal conditions and rest in adolescents. Images depict activation in adolescents during direct selfappraisals (You) and reflected self-appraisals from three perspectives—mother (Mom), best friend (Best), and classmates (Class)—in comparison to a resting baseline. Medial prefrontal cortex, medial posterior parietal cortex, and left temporal-parietal junction are encircled.

whether there are any differences in early adolescence at the neural level between taking your best friend's or your mother's perspective on your social skills and status, given that whether your best friend thinks you're popular is typically more relevant to your social self-definition than whether your mother thinks you're popular-and vice versa in academics. Our results suggest that a match between evaluative source and domain is associated with enhanced activity in MPFC and MPPC, the two regions most strongly affiliated with selfprocessing in previous neuroimaging studies. These results may also imply that this medial frontoparietal network may be particularly well suited to process information about the self in relation to others, rather than context-independent self-views, because these regions appear to be most active during reflected self-appraisals made from a perspective considered to be a valued source of information about the self in a given domain.

It is important to note that when greater activity is observed in a region during one condition (or in one group) relative to another, there can be two alternative modes of interpretation. Take our general finding that during direct self-appraisals, adolescents show relatively more activity than adults in regions commonly associated with self-reflection (MPFC and MPPC) as well as in circuitry affiliated with social perception and perspective-taking (TPJ, DMPFC, and pSTS). The first mode of interpretations would convey qualitative implications about adolescent development and neural function. For example, our results may suggest that adolescent self-construals incorporate reflected appraisals while those of adults typically do not-or put another way, that adolescents take more various "other" perspectives during direct self-appraisals while adults simply take one perspective on the self (their own). They may also imply that MPFC and MPPC are relatively more attuned to processing information about the self as perceived by others in relevant contexts, rather than a decontextualized self. The second possible interpretation tends to be more quantitative in nature. From this vantage point, our results may suggest adults are simply very efficient at processing perceived opinions of others when making self-construals; thus, less neural support is required for them to do so. In other words, do adults demonstrate relatively minimal levels of activity in these regions because they engage very little in reflected appraisals during direct self-reflection (as their self-concepts are relatively stable and decontextualized), or are they merely extremely efficient at carrying out this additional mental operation? Although this study cannot itself differentiate between these interpretations, prior studies of self-referential processing and other social perceptual tasks also imply that greater activity particularly in the medial frontoparietal network reflects attunement to task demands rather than cognitive inefficiency (Iacoboni et al., 2004; Kelley et al., 2002), suggesting the qualitative interpretation may be more parsimonious in our ROIs. We propose, therefore, that while reflected self-appraisal processes may be relatively similar in adolescents and adults, direct selfappraisals differ between the two age groups, in that adolescents may incorporate perspective-taking and other aspects of the reflected self-appraisal process into direct self-appraisals. 


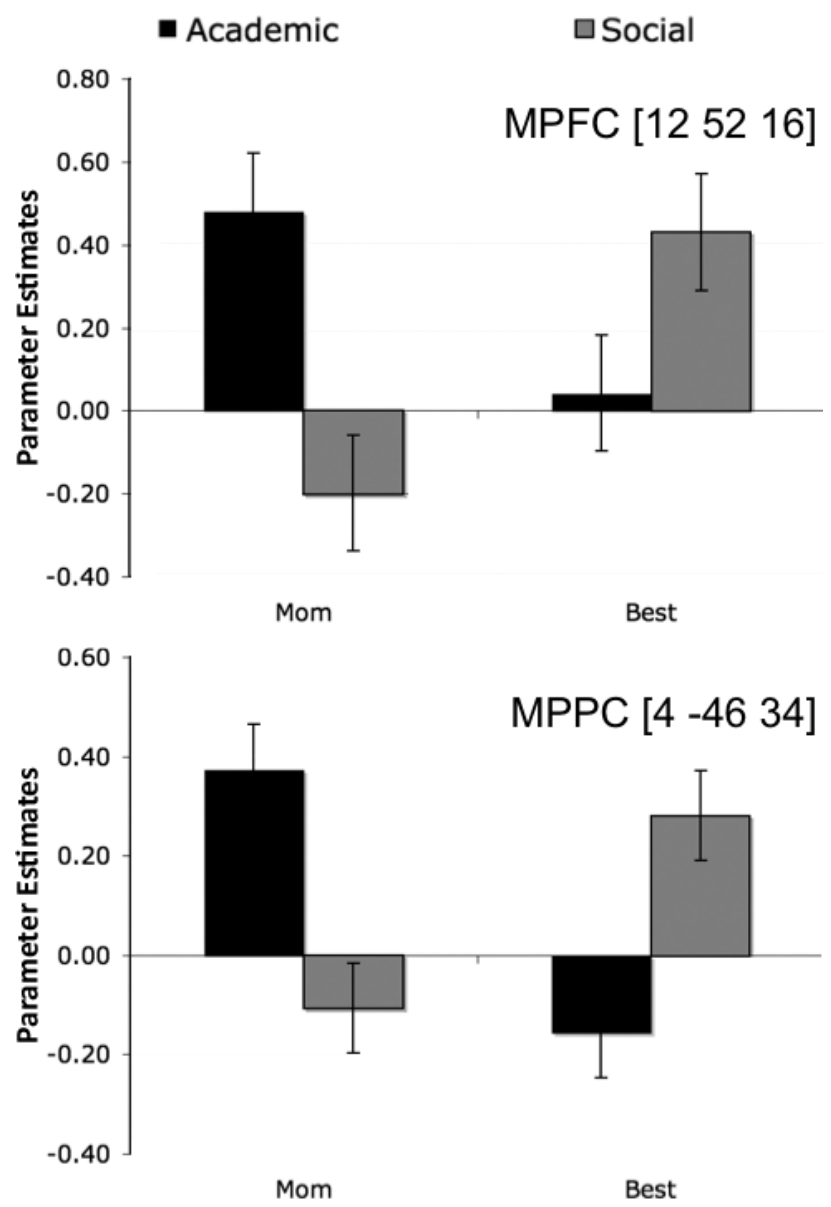

Figure 7. Interaction between reflected self-appraisal source (Mom or Best Friend) and self-concept domain academic or social). Mean activity in medial prefrontal cortex (MPFC) and medial posterior parietal cortex (MPPC) during reflected selfappraisals from the perspective of adolescents' mothers and best friends, depicted separately by academic and social domain, illustrates that activity in these regions is relatively enhanced when the domain matches the evaluative source's sphere of influence but does not significantly differ from baseline when taking the source's perspective on the self in a nonmatched domain.

If it is indeed the case that in early adolescence self-perceptions are more reliant on the perceived opinions of others, what takes place to change this dynamic by adulthood? After all, there has been an ongoing debate about whether this developmental stage is truly characterized by increased sensitivity to other's opinions about the self, or whether older adolescents and young adults simply realize that this is considered relatively immature (Lapsley, 1993; Vartanian \& Powlishta, 2001). One possibility suggested by Harter (1999) is that the propensity to engage in social comparison in late adolescence and early adulthood declines as individuals fuel self-development by comparison with ideal, internal guides (future and/or past selves) rather than peers (see also Sedikides \& Skowronski, 1995). We also propose that decontextualization of self-views may occur to a greater degree in cultures that are less relationally or collectively oriented.

Finally, it is worth mentioning that the ACC was the only region not commonly associated with selfor social perception that was found to be more active during direct self-appraisals in adolescents than adults. The dorsal ACC has been implicated in conflict monitoring, the distressing aspects of physical pain, as well as social pain and distress resulting from rejection (Eisenberger, Lieberman, \& Williams, 2003). Adolescents engaging in direct self-appraisals demonstrated significantly more activity in dorsal ACC, suggesting the possibility that this process-which may include ascertaining a variety of valued perspectives on the self (e.g., does my best friend, arch nemesis, or romantic crush think I'm popular?) and providing an integrative response (none of them do; I must not be popular)—could be distressing, conflict ridden, or socially painful. It would not be surprising to discover that for a teenager, admitting you are unpopular may cause a significant amount of distress. Alternatively, integrating several different perspectives (e.g., she thinks I'm popular, but he doesn't) may also lead to conflict and/or distress, which is consistent with prior behavioral work in developmental psychology as well (see Harter, 1999).

\section{Limitations}

Our study did not involve any low-level control conditions (such as reporting to which domain a stimulus refers) with which we could compare the various self-appraisal process conditions. This aspect of our design was a by-product of the fact that inclusion of the various appraisal conditions resulted in a functional run that was already very long. In order not to overly tax the younger participants in particular, no additional conditions could be added within a run. This led to a set of related limitations. One is that MPFC and MPPC have been implicated in the "default network," a system of brain regions that are typically more active during rest than externally focused tasks (Greicus, Krasnow, Reiss, \& Menon, 2003; Raichle et al., 2001). Therefore, our findings of less activity for adults than adolescents in these regions during direct selfappraisals versus rest might be due either to changes in direct self-appraisal processes or in the tonic activation of these regions during rest. Fur- 
thermore, MPPC and left TPJ have also been associated with episodic memory retrieval, tracking the perception that an item is old and the recollection of contextual details (for a review, see Wagner, Shannon, Kahn, \& Buckner, 2005). One could thus derive a slightly different but complementary interpretation of our results in these regions: Adults do not rely on episodic memories during direct selfappraisals in domains as primary as those assessed here. This is consistent with the idea that over many years, adults ultimately develop self-schema that should allow them to retrieve self-knowledge without the appeal to episodic memory (Lieberman et al., 2004; Rameson \& Lieberman, 2007). This is not to say that self-development does not continue over the life span. Rather, we expect that within any new domain the slow accumulation of experience and the fruits of social comparisons will cause relevant self-perceptions to coalesce and detach from the contributing episodic evidence.

It would be ideal for future studies to employ control conditions designed specifically to test whether our results are indeed due to the social cognitive aspects of the appraisal processes, and not an artifact of changes in the tonic activation of these regions while the brain is in a resting state. The possibility that there are changes in activity during rest does not explain the interactions between age group and source (appraisal condition) or between source and domain. Nevertheless, a recent article examining developmental changes in the default network found that the functional connectivity between ventral MPFC and other regions such as MPPC and lateral parietal areas (including TPJ) is significantly stronger in adults than children (Fair et al., 2008). Such results raise the possibility that each of these regions demonstrated significantly stronger activity in our adolescent sample because of sparse connectivity, which resulted in less efficient functioning as a network for self-perception and social perspective-taking.

Furthermore, many studies and reviews (Aichhorn et al., 2006; Frith \& Frith, 2003, 2006; Ruby \& Decety, 2003; Saxe, Carey, \& Kanwisher, 2004; Saxe \& Kanwisher, 2003; Saxe \& Wexler, 2005) propose that third-person perspective-taking, and perhaps reasoning about another individual's beliefs or mental states in particular, engages TPJ. However, there is still debate about whether the activity here is selective for theory of mind (Mitchell, 2008). Right hemisphere activity is usually emphasized in TPJ research, but lesion studies strongly suggest that the left hemisphere is also necessary for representing someone else's belief. For example, patients with damage to their left angular, supramarginal, and superior temporal gyri cannot perform above chance on false-belief tasks, although they are able to complete similar tasks that do not require mentalizing but are matched for linguistic difficulty and other computational demands (Apperly et al., 2004; Samson et al., 2004). In balance, we feel that the activity we observed in TPJ during reflected selfappraisals suggests that our participants were indeed attempting to put themselves in their mom's, best friends', or classmates' shoes to reason about what these sources think of themselves, and our results also imply that adolescents did this during direct self-appraisals as well (even when not specifically instructed to do so). Nevertheless, we remain mindful of the possibility that these neural systems were engaged for other reasons not discernible by our task design.

To address all these outstanding issues, the hypotheses we have proposed about the neural systems involved in self-appraisal processes during adolescence eventually need to be tested in a manner which would satisfy the "reverse inference problem." The validity of making deductions about the mental processes involved in a task solely on the basis of observing activation in a particular brain region may be limited by the selectivity of activity in that region, across a variety of task characteristics (Christoff \& Owen, 2006; Poldrack, 2006). For example, one may need to devote an initial fMRI run to defining subject-specific ROIs for firstand third-person perspective-taking via tasks that are not explicitly self-relevant, and then in subsequent fMRI runs ask participants of different ages to engage in direct and reflected self-appraisals (Saxe et al., 2004). We mention this to remind readers both that the ultimate contribution of developmental social cognitive neuroscience research will take much time and commitment to conducting programmatic research, but also that early efforts to generate future testable hypotheses are still an important step in the process, despite the likelihood that these will rely more heavily on reverse inference (just as social neuroscience and cognitive neuroscience research did in their early years).

\section{Future Directions and Conclusions}

One of the results from this study that may have the greatest impact on future research derives from the fact that adults engaged MPFC and MPPC more during reflected than direct self-appraisals, and adolescents engaged MPFC and MPPC more during reflected appraisals when they were made in a 
domain where a given evaluative source typically provides relevant feedback. Taken together, these findings suggest that this medial fronto-parietal network may be most attuned to relational selfprocessing. In other words, while general selfknowledge retrieval typically engages this medial fronto-parietal network more than processing that is not self-referential (e.g., Kelley et al., 2002), processing information about the self in relation to others may engage it the most. However, much more programmatic work is needed to confirm whether this modified interpretation about the functionality of MPFC and MPPC is correct. Additional studies may benefit from conducting cross-cultural comparisons of the neural correlates of self-appraisal processes. For example, by contrasting participants from relatively individualistic and collectivistic cultures, we may be able to observe whether relatively reduced activity in the medial fronto-parietal network during direct self-appraisals in adults represents routinization of self-referential processing, or a switch from relational to decontextualized self-knowledge.

Future research should also aim to collect functional and structural MRI data at multiple time points during childhood and adolescence, both in longitudinal and cross-sectional designs, to examine direct and reflected self-appraisal processes and their relation to brain development because many of the regions implicated in this study are late to mature (Shaw et al., 2008; Sowell, Thompson, \& Toga, 2004). This study was unfortunately limited to examining two groups with a substantial age gap (on average, 13 years) between them, as well as more age variability in the adult sample. Ideally, subsequent studies could evenly sample from middle childhood through adulthood to obtain a better grasp of when changes in neurocognitive processes belie the emergence of "mature" direct self-appraisals (which are relatively decontextualized, at least in mainstream American society). Such a finding may be able to provide some closure at last to the debate over whether the self is indeed more sensitive to perceived opinions of others (particularly peers) in early adolescence than during any other stage of development (Steinberg \& Silverberg, 1986; Vartanian, 2000; Vartanian \& Powlishta, 1996).

Finally, expanding social cognitive neuroscience research on the self to special populations such as individuals with autism spectrum disorders (ASD) is long overdue. One recent study suggests that there is a bidirectional influence between selfand social perception in adults with ASD; relative impairment in the one is associated with less success in the other (Lombardo, Barnes, Wheelwright, \& Baron-Cohen, 2007). Furthermore, adults with ASD appear to demonstrate hypoactivity in MPFC and MPPC during rest and may not engage these structures during self-knowledge retrieval (Cherkassky, Kana, Keller, \& Just, 2006; Kennedy, Redcay, \& Courchesne, 2006; Moran, Qureshi, Singh, \& Gabrieli, 2007). Ultimately, an investigation of the neural systems supporting self-concept development in children and adolescents with autism could also provide important new insights into the neurobiological basis of this disorder, as well as help us understand patterns of typical self-development.

In conclusion, we believe our initial inquiry into the neural correlates of reflected and direct selfappraisals in early adolescence can already make important contributions to developmental psychology. We discovered it is not so much in the process of making reflected self-appraisals that adolescents and adults differ but rather when thinking about oneself directly. Direct self-appraisals appear to incorporate perceived opinions of others to a greater extent in adolescents than adults, by engaging neural systems affiliated with perspectivetaking and mentalizing (including TPJ and DMPFC) more in this earlier stage of development. Furthermore, in our opinion the patterns of brain activity observed during adolescent reflected self-appraisals suggest a potential mechanism for the variability across domains in the power of parents and peers to affect self-development. Comparing between two domains (academic and social) and two sources (mothers and best friends), the medial fronto-parietal network commonly associated with self-reflection was most active when adolescents took someone else's perspective on the self in the domain that developmental psychologists have identified as most susceptible to that source's influence: the academic domain for mothers and the social domain for best friends. Perhaps such an enhanced pattern of neural activity in these regions is what leads a teenager over time to eventually incorporate a trait into his or her self-definition: I am popular (just like I believe my friends think), or I am smart (just like I believe my parents think). Taken together, this study provides fresh support at a level uncontaminated by self-report biases that during adolescence, self-perceptions may be strongly influenced by what we think other individuals think about us, and that the perceived opinions of peers and family members may carry more weight in some domains than others. These are not radically new ideas, but this is a novel form of evi- 
dence and an exciting technique that we hope will inspire future studies to examine the social and cognitive processes involved in self-development at the neural level.

\section{References}

Aichhorn, M., Perner, J., Kronbichler, M., Staffen, W., \& Ladurner, G. (2006). Do visual perspective tasks need theory of mind? Neuroimage, 30, 1059.

Apperly, I. A., Samson, D., Chiavarino, C., \& Humphreys, G. W. (2004). Frontal and temporo-parietal lobe contributions to theory of mind: Neuropsychological evidence from a false-belief task with reduced language and executive demands. Journal of Cognitive Neuroscience, 16, 1773-1784.

Baldwin, J. M. (1895). Mental development of the child and the race: Methods and processes. New York: Macmillan.

Bartusch, D. J., \& Matsueda, R. L. (1996). Gender, reflected-appraisals, and labeling: A cross-group test of an interactionist theory of delinquency. Social Forces, 75, 145-177.

Bouchey, H. A., \& Harter, S. (2005). Reflected appraisals, academic self-perceptions, and math/science performance during early adolescence. Journal of Educational Psychology, 97, 673-686.

Bracken, B. A. (1996). Handbook of self-concept. New York: Wiley.

Brown, B. (2004). Adolescents' relationships with peers. In R. Lerner \& L. Steinberg (Eds.), Handbook of adolescent psychology (pp. 363-394). New York: Wiley.

Cabeza, R., \& Nyberg, L. (2000). Imaging cognition II: An empirical review of 275 PET and fMRI studies. Journal of Cognitive Neuroscience, 12, 1-47.

Cavanna, A. E., \& Trimble, M. R. (2006). The precuneus: A review of its functional anatomy and behavioural correlates. Brain, 129, 564-583.

Chen, H., \& Lan, W. (1998). Adolescents' perceptions of their parents' academic expectations: Comparisons of American, Chinese-American, and Chinese high school students. Adolescence, 33, 385-390.

Cherkassky, V. L., Kana, R. K., Keller, T. A., \& Just, M. A. (2006). Functional connectivity in a baseline restingstate network in autism. Neuroreport, 17(16), 1687-1690.

Christoff, K., \& Owen, A. M. (2006). Improving reverse neuroimaging inference: Cognitive domain versus cognitive complexity. Trends in Cognitive Sciences, 10(8), 352.

Cole, D. A. (1991). Change in self-perceived competence as a function of peer and teacher evaluation. Developmental Psychology, 27, 682-688.

Cole, D. A., Maxwell, S. E., \& Martin, J. M. (1997). Reflected self-appraisals: Strength and structure of the relation of teacher, peer, and parent ratings to children's self-perceived competencies. Journal of Educational Psychology, 89, 55-70.

Cooley, C. H. (1902). Human nature and the social order. New York: Charles Scribner's Sons.
D'Argembeau, A., Collette, F., Van der Linden, M., Laureys, S., Del Fiore, G., Degueldre, C., et al. (2005). Selfreferential reflective activity and its relationship with rest: A PET study. Neuroimage, 25(2), 616-624.

D'Argembeau, A., Ruby, P., Collette, F., Degueldre, C., Balteau, E., Luxen, A., et al. (2007). Distinct regions of the medial prefrontal cortex are associated with selfreferential processing and perspective taking. Journal of Cognitive Neuroscience, 19(6), 935-944.

Damon, W., \& Hart, D. (1988). Self-understanding in childhood and adolescence. New York: Cambridge University Press.

Dumontheil, I., Burgess, P. W., \& Blakemore, S. J. (2008). Development of rostral prefrontal cortex and cognitive and behavioural disorders. Developmental Medicine and Child Neurology, 50(3), 168-181.

Eccles, J., Midgley, C., Wigfield, A., Bechanan, C. M., Reuman, D., Flanagan, C., et al. (1993). Development during adolescence: The impact of stage-environment fit on young adolescents' experiences in schools and in families. American Psychologist, 48, 90-101.

Eisenberger, N. I., Lieberman, M. D., \& Williams, K. D. (2003). Does rejection hurt? An fMRI study of social exclusion Science, 302, 290-292.

Fair, D. A., Cohen, A. L., Dosenbach, N. U., Church, J. A., Miezin, F. M., Barch, D. M., et al. (2008). The maturing architecture of the brain's default network. Proceedings of the National Academy of Sciences of the United States of America, 105(10), 4028-4032.

Felson, R. (1980). Communication barriers and the reflected appraisal process. Social Psychology Quarterly, 43, 223-233.

Felson, R. (1981). Social sources of information in the development of self. Sociological Quarterly, 22, 69-79.

Felson, R. (1985). Reflected appraisal and the development of self. Social Psychology Quarterly, 48, 71-78.

Felson, R. (1993). The (somewhat) social self: How others affect self-appraisals. In J. Suls (Ed.), The self in social perspective (Vol. 4, pp. 1-26). Hillsdale, NJ: Erlbaum.

Felson, R., \& Reed, M. (1986a). The effect of parents on the self-appraisals of children. Social Psychology Quarterly, 49, 302-308.

Felson, R., \& Reed, M. (1986b). Reference groups and self-appraisals of academic ability and performance. Social Psychology Quarterly, 49, 103-109.

Fink, G. R., Markowitsch, H. J., Reinkemeier, M., Bruckbauer, T., Kessler, J., \& Heiss, W. D. (1996). Cerebral representation of one's own past: Neural networks involved in autobiographical memory. Journal of Neuroscience, 16(13), 4275-4282.

Forman, S. D., Cohen, J. D., Fitzgerald, M., Eddy, W. F., Mintun, M. A., \& Noll, D. C. (1995). Improved assessment of significant activation in functional magnetic resonance imaging (fMRI): Use of a cluster-size threshold. Magnetic Resonance in Medicine, 33(5), 636-647.

Friston, K. J., Holmes, A. P., Price, C. J., Buchel, C., \& Worsley, K. J. (1999). Multisubject fMRI studies and conjunction analyses. Neuroimage, 10(4), 385-396. 
Friston, K. J., Penny, W. D., \& Glaser, D. E. (2005). Conjunction revisited. Neuroimage, 25(3), 661-667.

Frith, C. D., \& Frith, U. (2006). The neural basis of mentalizing. Neuron, 50(4), 531-534.

Frith, U., \& Frith, C. D. (2003). Development and neurophysiology of mentalizing. Philosophical Transactions of the Royal Society of London: Series B. Biological Sciences, 358(1431), 459-473.

Gardner, M., \& Steinberg, L. (2005). Peer influence on risk taking, risk preference, and risky decision making in adolescence and adulthood: An experimental study. Developmental Psychology, 41, 625-635.

Gillihan, S. J., \& Farah, M. J. (2005). Is self special? A critical review of evidence from experimental psychology and cognitive neuroscience. Psychological Bulletin, 131(1), 76-97.

Greicus, M. D., Krasnow, B., Reiss, A. L., \& Menon, V. (2003). Functional connectivity in the resting brain: A network analysis of the default mode hypothesis. Proceedings of the National Academy of Sciences of the United States of America, 100, 253-258.

Harter, S. (1999). The construction of the self: A developmental perspective. New York: Guilford.

Harter, S., Bresnick, S., Bouchey, H. A., \& Whitesell, N. R. (1997). The development of multiple role-related selves during adolescence. Development and Psychopathology, 9, 835-854.

Harter, S., Waters, P., \& Whitesell, N. R. (1998). Relational self-worth: Differences in perceived worth as a person across interpersonal contexts. Child Development, 69, 756-766.

Heatherton, T. F., Wyland, C. L., Macrae, C. N., Demos, K. E., Denny, B. T., \& Kelley, W. M. (2006). Medial prefrontal activity differentiates self from close others. Social Cognitive and Affective Neuroscience, 1, 18-25.

Hyatt, S. L., \& Collins, L. M. (2000). Using latent transition analysis to examine the relationship between perceived parental permissiveness and the onset of substance use. In J. S. Rose, L. Chassin, C. C. Presson, \& S. J. Sherman (Eds.), Multivariate applications in substance use research: New methods for new questions (pp. 259-288). Mahwah, NJ: Erlbaum.

Iacoboni, M., Lieberman, M. D., Knowlton, B. J., MolnarSzakacs, I., Moritz, M., Throop, C. J., et al. (2004). Watching social interactions produces dorsomedial prefrontal and medial parietal BOLD fMRI signal increases compared to a resting baseline. Neuroimage, 21, 1167-1173.

Ichiyama, M. A. (1993). The reflected appraisal process in small-group interaction. Social Psychology Quarterly, 56, 87-99.

Johnson, S. C., Baxter, L. C., Wilder, L. S., Pipe, J. G., Heiserman, J. E., \& Prigatano, G. P. (2002). Neural correlates of self-reflection. Brain, 125, 1808-1814.

Juvonen, J., Graham, S., \& Schuster, M. A. (2003). Bullying among young adolescents: The strong, the weak, and the troubled. Pediatrics, 112, 1231-1237.
Kahneman, D. (2003). A perspective on judgment and choice: Mapping bounded rationality. American Psychologist, 58, 697-720.

Kelley, W. M., Macrae, C. N., Wyland, C. L., Caglar, S., Inati, S., \& Heatherton, T. F. (2002). Finding the self? An event-related fMRI study. Journal of Cognitive Neuroscience, 14(5), 785-794.

Kennedy, D. P., Redcay, E., \& Courchesne, E. (2006). Failing to deactivate: Resting functional abnormalities in autism. Proceedings of the National Academy of Sciences of the United States of America, 103(21), 8275-8280.

Kenny, D. A., \& DePaulo, B. M. (1993). Do people know how others view them? An empirical and theoretical account. Psychological Bulletin, 114, 145-161.

Lapsley, D. K. (1993). Toward an integrated theory of adolescent ego development: The "new look" at adolescent egocentrism. American Journal of Orthopsychiatry, 63(4), 562-571.

Lieberman, M. D. (2007). Social cognitive neuroscience: A review of core processes. Annual Review of Psychology, $58,259-289$.

Lieberman, M. D., Jarcho, J. M., \& Satpute, A. B. (2004). Evidence-based and intuition-based self-knowledge: An fMRI study. Journal of Personality and Social Psychology, 87(4), 421-435.

Lieberman, M. D., \& Pfeifer, J. H. (2005). The self and social perception: Three kinds of questions in social cognitive neuroscience. In A. Easton \& N. Emery (Eds.), Cognitive neuroscience of emotional and social behavior (pp. 195-235). Philadelphia: Psychology Press.

Logothetis, N. K., \& Wandell, B. A. (2004). Interpreting the BOLD signal. Annual Review of Physiology, 66, 735769.

Lombardo, M. V., Barnes, J. L., Wheelwright, S. J., \& Baron-Cohen, S. (2007). Self-referential cognition and empathy in autism. PLOS ONE, 2(9), e883.

Maguire, E. A., Frith, C. D., \& Morris, R. G. (1999). The functional neuroanatomy of comprehension and memory: The importance of prior knowledge. Brain, 122, 1839-1850.

Marsh, H. W. (1990a). Self Description Questionnaire (SDQ) I: A theoretical and empirical basis for the measurement of multiple dimensions of preadolescent self-concept: A test manual and research monograph. Macarthur, NSW: Faculty of Education, University of Western Sydney.

Marsh, H. W. (1990b). Self Description Questionnaire (SDQ) II: A theoretical and empirical basis for the measurement of multiple dimensions of adolescent self-concept: A test manual and research monograph. Macarthur, NSW: Faculty of Education, University of Western Sydney.

Marshal, M. P., \& Chassin, L. (2000). Peer influence on adolescent alcohol use: The moderating role of parental support and discipline. Applied Developmental Science, 4, 80-88.

Mead, G. H. (1934). Mind, self and society from the standpoint of a social behaviorist. Chicago: University of Chicago Press. 
Mitchell, J. P. (2008). Activity in right temporo-parietal junction is not selective for theory-of-mind. Cerebral Cortex, 18, 262-271.

Mitchell, J. P., Banaji, M. R., \& Macrae, C. N. (2005). The link between social cognition and self-referential thought in the medial prefrontal cortex. Journal of Cognitive Neuroscience, 17, 1306-1315.

Mitchell, J. P., Macrae, C. N., \& Banaji, M. R. (2005). Forming impressions of people versus inanimate objects: Social-cognitive processing in the medial prefrontal cortex. Neuroimage, 26, 251-257.

Mitchell, J. P., Macrae, C. N., \& Banaji, M. R. (2006). Dissociable medial prefrontal contributions to judgments of similar and dissimilar others. Neuron, 50(4), 655-663.

Moran, J. M., Qureshi, A., Singh, M., \& Gabrieli, J. D. (2007, November). Neural underpinnings of self-referential processing in Asperger's syndrome. Paper presented at the Society for Neuroscience, San Diego, CA.

Mutti, M., Sterling, H., Martin, N., \& Spalding, N. (1988). Quick Neurological Screening Test II. Novato, CA: Academic Therapy Publications.

Nichols, T., Brett, M., Andersson, J., Wager, T., \& Poline, J. B. (2005). Valid conjunction inference with the minimum statistic. Neuroimage, 25(3), 653-660.

Ochsner, K. N., Beer, J. S., Robertson, E. R., Cooper, J. C., Gabrieli, J. D., Kihsltrom, J. F., et al. (2005). The neural correlates of direct and reflected self-knowledge. Neuroimage, 28(4), 797-814.

Ochsner, K. N., \& Lieberman, M. D. (2001). The emergence of social cognitive neuroscience. American Psychologist, 56, 717-734.

Olson, I. R., Plotzker, A., \& Ezzyat, Y. (2007). The Enigmatic temporal pole: A review of findings on social and emotional processing. Brain, 130, 1718-1731.

Pelphrey, K. A., Morris, J. P., \& McCarthy, G. (2004). Grasping the intentions of others: The perceived intentionality of an action influences activity in the superior temporal sulcus during social perception. Journal of Cognitive Neuroscience, 16, 1706-1716.

Pelphrey, K. A., Viola, R. J., \& McCarthy, G. (2004). When strangers pass. Processing of mutual and averted social gaze in the superior temporal sulcus. Psychological Science, 15, 598-603.

Pfeifer, J. H., Lieberman, M. D., \& Dapretto, M. (2007). "I know you are but what am I?" Neural bases of selfand social knowledge retrieval in children and adults. Journal of Cognitive Neuroscience, 19(8), 1323-1337.

Poldrack, R. A. (2006). Can cognitive processes be inferred from neuroimaging data? Trends in Cognitive Sciences, 10(2), 59.

Raichle, M. E., MacLeod, A. M., Snyder, A. Z., Powers, W. J., Gusnard, D. A., \& Shulman, G. L. (2001). A default mode of brain function. Proceedings of the National Academy of Sciences of the United States of America, 98, 676-682.

Rameson, L., \& Lieberman, M. D. (2007). Thinking about the self from a social cognitive neuroscience perspective. Psychological Inquiry, 18, 117-122.
Rex, D. E., Ma, J. Q., \& Toga, A. W. (2003). The LONI pipeline processing environment. Neuroimage, 19(3), 1033-1048.

Rosenberg, M. (1979). Conceiving the self. New York: Basic Books.

Ruby, P., \& Decety, J. (2003). What you believe versus what you think they believe: A neuroimaging study of conceptual perspective-taking. European Journal of Neuroscience, 17(11), 2475-2480.

Ruby, P., \& Decety, J. (2004). How would you feel versus how do you think she would feel? A neuroimaging study of perspective-taking with social emotions. Journal of Cognitive Neuroscience, 16(6), 988-999.

Samson, D., Apperly, I. A., Chiavarino, C., \& Humphreys, G. W. (2004). Left temporoparietal junction is necessary for representing someone else's belief. Nature Neuroscience, 7(5), 499.

Saxe, R. (2006). Uniquely human social cognition. Current Opinion in Neurobiology, 16(2), 235.

Saxe, R., Carey, S., \& Kanwisher, N. (2004). Understanding other minds: Linking developmental psychology and functional neuroimaging. Annual Review of Psychology, 55, 87-124.

Saxe, R., \& Kanwisher, N. (2003). People thinking about thinking people. The role of the temporo-parietal junction in "theory of mind." Neuroimage, 19(4), 1835-1842.

Saxe, R., \& Wexler, A. (2005). Making sense of another mind: The role of the right temporo-parietal junction. Neuropsychologia, 43(10), 1391-1399.

Sedikides, C., \& Skowronski, J. J. (1995). On the sources of self-knowledge: The perceived primacy of self-reflection. Journal of Social and Clinical Psychology, 14, 244270.

Shaw, P., Kabani, N. J., Lerch, J. P., Eckstrand, K., Lenroot, R., Gogtay, N., et al. (2008). Neurodevelopmental trajectories of the human cerebral cortex. Journal of Neuroscience, 28(14), 3586-3594.

Shearin, S. A. (2002). Parent-adolescent interaction: Influence on the academic achievement of African American adolescent males. In S. D. Miller (Ed.), Disability and the Black community (pp. 125-137), New York: Haworth Press.

Shrauger, J. S., \& Schoeneman, T. J. (1979). Symbolic interactionist view of self-concept: Through the looking glass darkly. Psychological Bulletin, 86, 549-573.

Simons-Morton, B. G., Hartos, J. L., \& Haynie, D. L. (2004). Prospective analysis of peer and parent influences on minor aggression among early adolescents. Health Education and Behavior, 31, 22-33.

Sowell, E. R., Thompson, P. M., \& Toga, A. W. (2004). Mapping changes in the human cortex throughout the span of life. Neuroscientist, 10(4), 372-392.

Steinberg, L., \& Morris, A. S. (2001). Adolescent development. Annual Review of Psychology, 52, 83-110.

Steinberg, L., \& Silverberg, S. B. (1986). The vicissitudes of autonomy in early adolescence. Child Development, 57(4), 841-851.

Tice, D. M., \& Wallace, H. M. (2005). The reflected self: Creating yourself as (you think) others see you. In M. 
R. Leary, G. MacDonald, \& J. P. Tangney (Eds.), Handbook of self and identity (pp. 91-105). New York: Guilford.

Vartanian, L. R. (1997). Separation-individuation, social support, and adolescent egocentrism: An exploratory study. Journal of Early Adolescence, 17, 245-270.

Vartanian, L. R. (2000). Revisiting the imaginary audience and personal fable constructs of adolescent egocentrism: A conceptual review. Adolescence, 35(140), 639661.

Vartanian, L. R., \& Powlishta, K. K. (1996). A longitudinal examination of the social-cognitive foundations of adolescent egocentrism. Journal of Early Adolescence, 16, 157-178.

Vartanian, L. R., \& Powlishta, K. K. (2001). Demand characteristics and self-report measures of imaginary audience sensitivity: Implications for interpreting age differences in adolescent egocentrism. Journal of Genetic Psychology, 162(2), 187-200.

Vogeley, K., Bussfeld, P., Newen, A., Herrmann, S., Happe, F., Falkai, P., et al. (2001). Mind reading: Neural mechanisms of theory of mind and self-perspective. Neuroimage, 14, 170-181.

Wagner, A. D., Shannon, B. J., Kahn, I., \& Buckner, R. L. (2005). Parietal lobe contributions to episodic memory retrieval. Trends in Cognitive Sciences, 9(9), 445-453.
Wang, A. T., Lee, S. S., Sigman, M., \& Dapretto, M. (2006). Developmental changes in the neural basis of interpreting communicative intent. Social Cognitive and Affective Neuroscience, 1, 107-121.

Wechsler, D. (1999). Wechsler Abbreviated Scale of Intelligence (WASI). San Antonio, TX: Harcourt Assessment.

Wigfield, A., Eccles, J., Yoon, K. S., Harold, R. D., Arbreton, A. J. A., \& Blumenfeld, P. C. (1997). Changes in children's competence beliefs and subjective task values across the elementary school years: A three-year study. Journal of Educational Psychology, 89, 451-469.

Woods, R. P., Dapretto, M., Sicotte, N. L., Toga, A. W., \& Mazziotta, J. C. (1999). Creation and use of a Talairachcompatible atlas for accurate, automated, nonlinear intersubject registration, and analysis of functional imaging data. Human Brain Mapping, 8(2-3), 73-79.

Woods, R. P., Grafton, S. T., Holmes, C. J., Cherry, S. R., \& Mazziotta, J. C. (1998). Automated image registration: I. General methods and intrasubject, intramodality validation. Journal of Computer Assisted Tomography, 22(1), 139-152.

Woods, R. P., Grafton, S. T., Watson, J. D., Sicotte, N. L., \& Mazziotta, J. C. (1998). Automated image registration: II. Intersubject validation of linear and nonlinear models. Journal of Computer Assisted Tomography, 22(1), 153-165. 